\title{
Calcium alginate based antimicrobial film dressings for potential healing of infected diabetic foot ulcers
}

\author{
Asif Ahmed ${ }^{1}$, Joshua Boateng ${ }^{1 *}$ \\ ${ }^{1}$ Department of Pharmaceutical, Chemical and Environmental Sciences, Faculty of \\ Engineering and Science, University of Greenwich at Medway, Central Avenue, Chatham \\ Maritime, ME4 4TB.
}

*Correspondence: j.s.boateng@gre.ac.uk, joshboat40@gmail.com

\begin{abstract}
Background: Diabetic foot ulcers are susceptible to infection and non-medicated dressings are ineffective because they have no antimicrobial activity. This study aimed to develop antimicrobial films to deliver ciprofloxacin for treating bacterial infection.

Results/Methodology: Ciprofloxacin loaded calcium alginate films were characterized for porosity, swelling, equilibrium water content, water absorption, water vapour transmission, evaporative water loss, moisture content, mechanical strength, adhesion, infrared spectroscopy, scanning electron microscopy, X-ray diffraction, drug release, cytotoxicity and antimicrobial activity against $E$. coli, $S$. aureus and $P$. aeruginosa. Films were transparent, flexible, uniform, with ideal moisture handling, maximum drug release within 90 min, killing bacteria within $24 \mathrm{~h}$ and highly biocompatible with human keratinocyte cells.
\end{abstract}

Conclusions: The results confirmed successful design of biocompatible dressings effective against Gram positive and Gram negative bacteria.

Keywords: Antibacterial activity, calcium alginate, chronic wounds, ciprofloxacin, diabetic foot ulcers, glycerol, moisture handling, solvent cast film, wound healing. 


\section{Introduction}

The prevalence of chronic wounds, including diabetic foot, leg and pressure ulcers has increased significantly around the world. It is predicted that in 20 years from 2005 to 2025 , the number of patients with chronic wounds will increase from 60.4 million to 63.8 million [1]. Foot ulcerations are very common in diabetic patients and it is estimated that more than 60, 000 of these patients are likely to have foot ulcers at any given time in England alone [2]. The annual cost of wound care for wound dressings and other materials in the United Kingdom (UK) alone was $£ 420$ million in 2014 and will increase to $£ 461$ million from 2014 to 2019 [3]. It is reported that $£ 972$ million to $£ 1.13$ billion was spent for foot ulceration and amputation in diabetes in $2014-15$, which is equivalent to $0.72-0.83 \%$ of the National Health Service budget in England [2,4].

According to statistics for England and Wales in 2014-16, about $45.6 \%$ and $42.8 \%$ of foot ulcer episodes in patients with type 1 and type 2 diabetes respectively, had bacterial infection [5]. Various clinical studies have reported that the most predominant bacterial species in diabetic foot ulcers (DFUs) are Staphylococcus aureus, Pseudomonas aeruginosa and Escherichia coli [6-9]. A clinical study reported that $S$. aureus and P. aeruginosa were isolated from diabetic foot infections in about $38.4 \%$ and $17.5 \%$ of cases respectively [7], whilst isolates of E. coli was found in about $14.6 \%$ of cases [9]. In another study, 84 patients with infected DFUs were investigated and it was found that the prevalence of S. aureus was the most common and approximately $50 \%$ of the isolates were resistant to methicillin [10]. Therefore, the demand for developing antimicrobial wound dressings is increasing. Medicated film dressings can also reduce the cost burden as a result of lower production costs $[11,12]$ in comparison with other advanced alternatives such as tissue engineered substitutes. Further, antimicrobial dressings applied locally to the wound site avoid unwanted effects; interfering with the healing process and inducing resistance to the loaded active ingredient [13].

Current commercial film dressings are semipermeable, thin, flexible sheets of clear polyurethane incorporating an adhesive coating on one side to allow adherence to the skin. They are highly elastic, conform to any contour of the body and are suitable as primary or secondary dressings. Their transparency allows useful visualization of the wound bed during healing without the need for removal, therefore reducing the chances of traumatising the wound and causing pain. They are permeable to gases (water vapour, oxygen and carbon dioxide) but impermeable to bacteria and liquid water (exudates) due to semi-occlusive 
nature. This means that oxygen is allowed into the wound to promote healing while, water vapour and carbon dioxide produced can easily escape [14] and this helps to achieve lower overall infection rates than traditional dressings such as gauze and cotton wool. It was reported that films promote faster wound healing, decrease pain, cause less scaring, allow visual wound assessment and facilitate patient mobility and hygiene [15].

In recent years, novel film dressings made of natural, synthetic or semi synthetic polymers such as alginate, chitosan, collagen, gelatine, polyvinyl alcohol, polyethylene oxide have been reported [16,17]. Calcium alginate (CA) extracted from brown seaweed, consists of homo polymeric regions of mannuronic acid (M) and guluronic acid (G). Dressings obtained from alginates form an ordered structure in solution and produce strong gels on the wound surface upon exudate absorption $[17,18]$. Therefore, they permit permeation of water vapour, oxygen and metabolites which can facilitate the healing of ischemic DFUs while protecting the wound bed against debris and microbial penetration. Furthermore, CA has hemostatic and antimicrobial properties, making the dressings effective in healing wounds $[19,20]$.

Ciprofloxacin (CIP), is a fluoroquinolone derivative, which is highly effective against both Gram positive and Gram negative bacteria due to its low minimum inhibitory concentration (MIC) [21-23]. The MIC for CIP is reported for E. coli, S. aureus and P. aeruginosa as $0.015 \mu \mathrm{g} / \mathrm{ml}, 0.5 \mu \mathrm{g} / \mathrm{ml}$ and $0.25 \mu \mathrm{g} / \mathrm{ml}$ respectively [24]. The chemical structure of CIP is 1-cyclopropyl-6-fluoro-4-oxo-7-(piperazin-1-yl)-1,4-dihydroquinoline-3carboxylic acid with the 6-fluoro and cyclopropyl substituent responsible for antibacterial activity. In addition, the 7-piperazino group has been found to be responsible for inhibiting Pseudomonas spp. CIP acts by inhibiting topoisomerase II (DNA gyrase) and topoisomerase IV, which are responsible for ATP-dependent negative supercoiling of bacterial DNA replication, transcription, repair and recombination [25].

There are many alginate based commercial dressings on the market but CIP loaded alginate based dressings are currently not available whilst recent studies lack data showing effective bacterial inhibitions and low cytotoxicity. Therefore, in this study, CIP loaded CA based films prepared by solvent casting technique were characterized for different functional properties expected for effective wound dressings. To the best of our knowledge, there has been no research study undertaken on alginate-glycerol-ciprofloxacin composites in the form of film dressings to potentially treat infected DFUs. A related study was previously reported, 
where CIP was loaded in composite sodium alginate/gelatine films, [26] whilst other studies did not report on films $[27,28]$. Though two studies reported complete eradication of $E$. coli and $P$. aeruginosa, [27, 29], no studies of CIP loaded dressings have shown complete killing of $S$. aureus. The hypothesis is that, low but effective antibacterial doses of CIP will reduce local cytotoxicity and enhance cell viability (biocompatibility) when applied over long periods as happens in chronic wounds such as DFUs. Finally, this is the first study testing the biocompatibility of CIP loaded film dressings using human keratinocyte skin cells. .

\section{Materials and methods}

\section{Formulation development and optimisation}

\section{Preliminary formulation of blank (BLK) films}

Different $1 \%$ w/v gels were prepared by dissolving CA (Sigma Aldrich, Gillingham, UK) in different concentrations (0.005-0.028 M) of sodium carbonate solution (Fisher Scientific, Loughborough, UK). Furthermore, different amounts (9.1, 20.0, 33.3, 42.8 and $50.0 \%$ ) of glycerol (GLY) (Fisher Scientific, Loughborough, UK) based on the total polymer weight $(\mathrm{w} / \mathrm{w})$ were added to the gels after which $20 \mathrm{~g}$ of each gel was poured into Petri dishes with diameter of $86 \mathrm{~mm}$ and dried $\left(30^{\circ} \mathrm{C}\right)$ for $18 \mathrm{~h}$ to obtain films. The films were visually examined identify any physical defects.

\section{Preparation of drug loaded (DL) films}

Based on preliminary observation of the plasticised films prepared above, drug was loaded into the optimized film containing 33.3\% (w/w) GLY. Initially CIP (Sigma Aldrich, Gillingham, UK) was dissolved in $0.014 \mathrm{M}$ sodium carbonate solution from an initial stock solution $(250 \mu \mathrm{g} / \mathrm{ml})$ of the drug. To obtain the DL films, GLY was dissolved in sodium carbonate solution by stirring at $50^{\circ} \mathrm{C}$ for $10 \mathrm{~min}$ and then drug solution (to achieve drug concentrations of $0.005,0.010$ and $0.025 \% \mathrm{w} / \mathrm{v}$ ) was mixed with the plasticised gel under continuous stirring. After that, CA powder was added in tiny amounts to avoid lump formation with continuous stirring for $3 \mathrm{~h}$. Finally, $20 \mathrm{~g}$ of the gels were poured into Petri dishes and dried in a $30^{\circ} \mathrm{C}$ oven for $18 \mathrm{~h}$ to obtain the films, which were wrapped with parafilm and kept in a desiccator until required. 


\section{Fluid handling properties}

Porosity

The porosity of the films was measured using a previously reported ethanol displacement method [30-32]. Briefly, the samples were immersed in $10 \mathrm{ml}$ of ethanol (Fisher Scientific, Loughborough, UK) over a period of $3 \mathrm{~h}$ to achieve saturation level. The samples were initially weighed before immersing into the solvent and reweighed after being saturated. The total pore volume was initially determined from the thickness and diameter of the films and subsequently used to calculate film porosity $(n=3)$ according equation 1 :

Porosity $(\%)=\frac{W i-W_{0}}{\rho \text { eth } V_{0}} \times 100$

Where, $\mathrm{W}_{1}$ is the saturated weight and $\mathrm{W}_{0}$ is the dry weight of the samples. $\mathrm{V}_{0}$ is the total pore volume calculated from its geometrical dimensions and $\rho_{\text {eth }}$ is the density of ethanol $(0.789$ $\left.\mathrm{g} / \mathrm{cm}^{3}\right)$.

Water absorption, equilibrium water content and swelling index

The water absorption (Aw), equilibrium water content (EWC) and swelling index (Is) of all the films were measured using aqueous based simulated wound fluid (SWF) at $\mathrm{pH}$ of 7.5 , prepared from bovine serum albumin $(\mathrm{BSA})=2 \%(\mathrm{w} / \mathrm{w})$, calcium chloride- $0.02 \mathrm{M}$, sodium chloride- $0.4 \mathrm{M}$, tris (hydroxymethyl) aminomethane-0.08 M (all from Fisher Scientific, Loughborough, UK). To determine the Aw, samples were weighed and kept in 10 $\mathrm{ml}$ of SWF over a $24 \mathrm{~h}$ period at a temperature of $37^{\circ} \mathrm{C}$. After $24 \mathrm{~h}$, samples were carefully wiped using tissue paper to remove excess SWF and reweighed and the Aw calculated using equation 2 below. Each measurement was performed in triplicate $(n=3)$

$A w(\%)=\frac{W s-W i}{W i} \times 100$

Where Ws is the swollen weight and Wi is the initial weight before immersion into SWF.

To determine the EWC, the same procedure was followed as for Aw, however, the EWC $(n=3)$ was calculated using equation 3 below.

$E W C(\%)=\frac{W s-W i}{W s} \times 100$

For swelling, the weighed samples were dipped into $10 \mathrm{ml}$ of SWF (at ambient temperature) and changes in weight of swollen films recorded at 15 min intervals up to $1 \mathrm{~h}$ and subsequently every $60 \mathrm{~min}$ until $5 \mathrm{~h}$. The swelling index (Is) was calculated $(n=3)$ from equation 4 below. 
Is $(\%)=\frac{W s t-W i}{W d} \times 100$

Where $\mathrm{W}_{\mathrm{i}}$ is the dry weight of samples before hydration and $\mathrm{W}_{\text {st }}$ is the swollen weight of samples at different hydration times.

Further, the effect of drug concentration on Aw, EWC and Is was determined.

\section{Water vapour transmission rate}

With the help of epoxy glue, the films were used to cover fully the mouth of $25 \mathrm{ml}$ Falcon tubes with diameter of $15 \mathrm{~mm}$. The tubes were previously filled with of $15 \mathrm{ml}$ water which allowed an air gap of $8 \mathrm{~mm}$ between the surface of the water and the films. The whole assembly was then put into an oven $\left(37^{\circ} \mathrm{C}\right)$ with air circulation at for $24 \mathrm{~h}$. The WVTR $(n=$ 3) was calculated using equation 5 :

WVTR $=\frac{\mathrm{Wb}-\mathrm{Waf}}{\mathrm{A}} \times 10^{6} \mathrm{~g} / \mathrm{m}^{2} \mathrm{day}^{-1}$

Where $\mathrm{A}=$ area of the mouth of the Falcon tube $\left(\pi \mathrm{r}^{2}\right), \mathrm{W}_{\mathrm{b}}$ and $\mathrm{W}_{\mathrm{af}}$ are the weights of the whole setup before and after placing into oven respectively.

\section{Evaporative water loss}

The films were placed in SWF and incubated in an oven at $37^{\circ} \mathrm{C}$ for $24 \mathrm{~h}$. After that films were removed and dried at $37^{\circ} \mathrm{C}$ for a further $24 \mathrm{~h}$ with sample weight measured at specified time intervals. Evaporative water loss $(n=3)$ was calculated using equation 6 below:

Water loss $(\%)=\frac{W_{t}}{W_{i}} \times 100$

Where $W_{t}$ is the weight of film after time ' $t$ ' and $W_{i}$ represents the initial weight after $24 \mathrm{~h}$ immersion in SWF.

\section{Moisture content}

The residual moisture content was analysed using thermogravimetric analysis (TGA) by employing a Q5000-IR TGA instrument (TA Instruments, Crawley, UK). The film sample $(1.0-1.5 \mathrm{mg})$ was loaded and analysed by heating from $25^{\circ} \mathrm{C}-300^{\circ} \mathrm{C}$ at $10^{\circ} \mathrm{C} / \mathrm{min}$ under 
constant stream of nitrogen gas flowing a $50 \mathrm{~mL} / \mathrm{min}$. The residual moisture content was determined at $100^{\circ} \mathrm{C}$ by calculating the percentage weight change at that temperature with the help of the TA Instruments Universal Analysis 2000 software.

\section{Physico-chemical Characterisation}

\section{Texture analysis}

\section{Mechanical properties}

The tensile properties (tensile strength, Young's modulus and percent elongation) of the films were analysed by stretching on a TA HD Texture analyser (Stable Microsystem Ltd., Surrey, UK) in tensile mode equipped with a load maximum load of $5 \mathrm{~kg}$ and a Texture Exponent 32 software program for data plotting and display. The films with dimensions of 80 $\mathrm{mm}$ total length, $30 \mathrm{~mm}$ gauge length and width of $3.5 \mathrm{~mm}$ were cut into dumb-bell shapes and their average thickness entered into the software programme. The films were then stretched between two tensile grips using the following settings: test speed $(0.10 \mathrm{~mm} / \mathrm{sec})$, trigger force $(0.05 \mathrm{~N})$, and pre-test speed $(1.00 \mathrm{~mm} / \mathrm{sec})$ and post-test speed $(10.00 \mathrm{~mm} / \mathrm{sec})$ at respectively. Initially, the test was carried out on the BLK films containing different percentages of plasticizer (1\% CA-9.1\% GLY, 1\% CA-20.0\% GLY, 1\% CA-33.3\% GLY, $1 \%$ CA-42.8\% GLY and 1\% CA-50.0\% GLY) to define the formulation with optimum mechanical properties to use for drug loading [33]. Subsequently, DL films were tested to determine the effect of drug loading. Three main tensile properties (tensile strength, Young's modulus and elongation at break) were calculated $(n=3)$ from equations 7,8 and 9 [17].

Tensile strength $\left(\mathrm{N} / \mathrm{mm}^{2}\right)=\frac{\text { Force at break }(\mathrm{N})}{\text { Initial cross sectional area }\left(\mathrm{mm}^{2}\right)}$

Young's modulus $(\mathrm{MPa})=\frac{\text { Slope }}{\text { Film thickness }(\mathrm{mm}) \mathrm{x} \text { cross-head speed }(\mathrm{mm} / \mathrm{s})}$

Elongation at break $(\%)=\frac{\text { Increase in length }(\mathrm{mm}) \text { at break }}{\text { Initial film length }(\mathrm{mm})} \times 100$ 
In-vitro adhesion

The adhesive test was performed using a texture analyser (TA.HD. plus) (Stable Microsystem Ltd., Surrey, UK) to evaluate the adhesive properties, that is; stickiness (peak adhesive force - PAF), total work of adhesion (WOA) and cohesiveness of the films. Before the experiment, $500 \mu \mathrm{l}$ of SWF containing $2 \% \mathrm{w} / \mathrm{v}$ bovine serum albumin (Fisher Scientific, Loughborough, UK), representing protein rich exudate, was spread on the surface of set gelatine $(6.67 \% \mathrm{w} / \mathrm{w})$ gel layer to mimic a chronic wound surface and the gel was placed on the stationary platform of the texture analyser. Samples were attached to a cylindrical stainless steel probe (35 mm diameter) with the help of double sided adhesive tape and the probe set to approach the model wound surface. Based on previous report [33], measurements were obtained using the following settings: pre-test and test speeds of $0.5 \mathrm{~mm} / \mathrm{s}$ respectively; post-test speed of $1 \mathrm{~mm} / \mathrm{s}$; auto trigger force of $0.05 \mathrm{~N}$; applied force at $1 \mathrm{~N}$; contact time of $60 \mathrm{~s}$ and return distance of $10 \mathrm{~mm}$. The adhesive properties were calculated using the Texture Exponent 32 software. The results were obtained from the analysis of three different parts of the films and mean \pm SD calculated for each adhesive parameter.

Attenuated total reflectance Fourier transform infrared (ATR-FTIR) spectroscopy and Infrared (IR) mapping

A FTIR spectrophotometer (Two Perkin Elmer, USA) was used in combination with a crystal diamond universal attenuated total reflectance (UATR) to characterize pure CIP and pure CA as well as the BLK and DL films. Samples were placed to cover the crystal and the metal tip turned around in order to allow intimate contact of the samples with the crystal. Spectra were recorded in transmission mode between 650 and $4000 \mathrm{~cm}^{-1}$ at a resolution of 4 $\mathrm{cm}^{-1}$ (4 scans per spectrum). A background spectrum was taken before analysing the samples to calibrate the instrument. IR mapping of the surface of the films was performed using a Nicolet $^{\mathrm{TM}}$ iN $^{\mathrm{TM}} 10 \mathrm{MX}$ Infrared Imaging Microscope (Thermo Fisher Scientific, USA) equipped with OMNICTM Picta $^{\mathrm{TM}}$ to investigate the chemical distribution of materials within the polymeric films. Liquid nitrogen was poured into the system to analyse the samples with cooled detector in the measurement range $4000-650 \mathrm{~cm}^{-1}$ and spectra were collected in reflection mode with 3s collection time. For each spectrum, 70 spots and 16 scans were combined. Four characteristic peaks for the films (CA-BLK and CA-DL) were selected as spectral markers of pure CA. 
The surface morphology of the films was observed by a Hitachi SU 8030 scanning electron microscope (Hitachi High-Technologies, Germany) with an operating voltage of 10 $\mathrm{kV}$. The samples were fixed onto aluminium stubs and chromium coated with a sputter coater for $5 \mathrm{~min}$. The SEM micrographs were taken at working distances between $8.1 \mathrm{~mm}$ to 9.0 $\mathrm{mm}$ at x6000 magnification with the help of i-scan 2000 software. The images were captured at three different areas of the films to evaluate the consistency of the microstructures.

\section{In-vitro drug dissolution}

Drug content uniformity (DCU) and the total drug content (TDC) of the films were investigated before drug dissolution to ensure uniform drug distribution within the film matrix. The DCU was determined by cutting the films into circular strips (6 mm diameter) from three different locations and accurately weighed. The films were initially hydrated in 10 $\mathrm{ml}$ of purified water at $37{ }^{\circ} \mathrm{C}$ and then left overnight with continuous stirring to allow complete dissolution. To determine TDC, the whole film was hydrated in $50 \mathrm{ml}$ of purified water. The quantity of drug in solution was determined by HPLC after filtration.

For the drug dissolution, a diffusion cell designed within our laboratories at the University of Greenwich was employed. The diffusion cell has wire mesh on the top where the samples are placed and SWF ( $\mathrm{pH} 7.5)$ without BSA was used as a dissolution medium in the receptor compartment. About $30 \mathrm{ml}$ of dissolution medium was poured into the cell with the liquid medium just touching the lower surface of the films to ensure adequate hydration. A magnetic bead was previously placed into the cell and the entire system was then inserted into a constant temperature water bath offset to $37^{\circ} \mathrm{C}$ and continuously stirred at $600 \mathrm{rpm}$ throughout. Aliquots $(1 \mathrm{ml})$ were sampled from the dissolution medium at different time points and replaced with the same volume of SWF to maintain a constant volume. The experiments of each sample (1\% CA- $0.005 \%$ CIP, $1 \%$ CA- $0.010 \%$ CIP and 1\% CA- $0.025 \%$ CIP) were performed in triplicate and the mean cumulative percentage drug release from the films was calculated using a standard calibration curve.

\section{HPLC analysis}

HPLC was performed using the Agilent 1200 series HPLC (Agilent Technologies, UK) with a quaternary pump, an auto sampler and Chemstation ${ }^{\circledR}$ software program for controlling the instrument and analysing data. . A C18 analytical column (YMC-Pack ODS- 
AQ AQ-303-5, 250x4.6 mm I.D, S-5 $\mu \mathrm{m}, 120 \mathrm{~A}$, NO.042512322) was used as a stationary phase. The mobile phase consisted of a two solvent isocratic system in which $2 \%$ acetic acid and acetonitrile were used in the ratio of $70: 30$ at a flow rate of $1 \mathrm{ml} / \mathrm{min}$. The UV detector wavelength for CIP was set at $280 \mathrm{~nm}$ and $20 \mu \mathrm{l}$ volumes were injected during each run. The stock solution of CIP was prepared in $2 \%$ acetic acid at a concentration of $500 \mu \mathrm{g} / \mathrm{ml}$. The working solutions of CIP were prepared by diluting the required volumes of the stock solution with mobile phase to obtain concentrations ranging from 1 to $100 \mu \mathrm{g} / \mathrm{ml}$ in triplicate for the calibration curve $\left(189.35 \mathrm{x}, R^{2}=0.9993\right)$. The reproducible retention time for CIP was $4.89 \mathrm{~min}$.

\section{Drug release kinetics}

The mechanism of drug release was investigated by measuring the kinetics of CIP release from the polymeric films and fitting the release data to four kinetic equations; Higuchi, Korsmeyer-Peppas, zero order and first order equations [34]. Korsmeyer-Peppas equation (10) was used to understand the mechanism of drug release.

$\ln \left(\frac{Q t}{Q \infty}\right)=\ln k+n \ln t$

$\mathrm{Q}_{\mathrm{t}}$ and $\mathrm{Q}_{\infty}$ are the absolute cumulative amounts of drug released at time $(\mathrm{t})$ and infinite time respectively, $\mathrm{k}$ is a constant related to the structural and geometrical characteristic of the films and $\mathrm{n}$ is the release exponent.

\section{Biological characterisation}

Methylthiazolyldiphenyl-tetrazolium (MTT) bromide- (cell viability) assay

In vitro cytotoxicity of CIP loaded films was evaluated on adult human primary epidermal keratinocytes (PEK) (PCS-200-011, ATCC) (LGC Standards, Middlesex, UK). Films were cut into $6 \mathrm{~mm}$ circular discs and sterilized overnight using UV light. The samples were then immersed in $1.5 \mathrm{ml}$ of dermal cell basal medium (PCS-200-030, ATCC) supplemented with keratinocytes growth kit (PCS-200-040, ATCC) (LGC Standards, Middlesex, UK) for $24 \mathrm{~h}$ in a Heracell $150 \mathrm{i} \mathrm{CO} 2$ incubator, Thermo Scientific) at $37^{\circ} \mathrm{C}$. The liquid samples were filtered through a $0.2 \mu \mathrm{m}$ filter and the filtrate collected. In this study, cytotoxicity test was performed by indirect contact of the samples with the cells. The PEK cells were separately cultured in 96-well tissue-culture polystyrene plates at a density of 1000 cells/well in the complete growth medium for $5 \mathrm{~h}$ to allow cell attachment. After that, the media were replaced with extraction media and the cells were re-incubated for up to $72 \mathrm{~h}$. 
The viability of the cells cultured with each of the sample extraction media was finally determined using the ATCC recommended protocol by adding $10 \mu \mathrm{l}$ of MTT reagent (Thermo Fisher Scientific, Paisley, UK) to each well including those containing only the medium (blank) and incubated at $37^{\circ} \mathrm{C}$ in $5 \%(\mathrm{v} / \mathrm{v}) \mathrm{CO}_{2}$ for $4 \mathrm{~h}$. Subsequently, the media was removed and purple formazan crystals formed were solubilized with $100 \mu$ l of DMSO (Fisher Scientific, Loughborough, UK). After incubating at $37^{\circ} \mathrm{C}$ in $5 \%(\mathrm{v} / \mathrm{v}) \mathrm{CO}_{2}$ for another 30 min, the absorbance of each well at $492 \mathrm{~nm}$ was recorded with the help of a microtiter plate reader (Multiskan FC, Thermo Scientific) that had a SkanIt Multiskan FC 3.1 software (Thermo scientific). The cell viability (\%) was reported relative to the negative control wells not exposed to the dressings and blank well containing only fresh cell culture medium. Cells treated with only Triton-X-100 $(0.01 \% \mathrm{w} / \mathrm{v})$ were also tested as positive control. Each experiment was carried out in triplicates $(n=3)$ and repeated three times. The percentage cell viability was calculated as shown in equation 11 below.

Cell viability $(\%)=\frac{\mathrm{At}-\mathrm{Ab}}{\mathrm{Ac}-\mathrm{Ab}} * 100$

Where At, $\mathrm{Ab}$ and Ac are the absorbance of tested samples, blank (medium only) and negative control (untreated cells) respectively.

\section{Antibacterial study}

Antimicrobial activity of the films containing different amounts $(0.005,0.010$ and $0.025 \% \mathrm{w} / \mathrm{v}$ ) of CIP were evaluated using turbidimetric, Kirby-Bauer disc diffusion and time kill assays. Briefly, bacterial inocula of E. coli (ATCC 25922), S. aureus (ATCC 29213) and P. aeruginosa (ATCC 27853) (from the University of Greenwich microbiology laboratories) were prepared from fresh colonies on Mueller Hinton (MH) agar \# 3 technical (Fisher Scientific, Loughborough, UK). After overnight incubation, the bacterial suspensions were adjusted to $0.5 \mathrm{McF}$ arland standard representing $\sim 10^{8} \mathrm{CFU} / \mathrm{ml}$. In the turbidimetric method, $0.1 \mathrm{ml}$ of bacteria suspensions were added to each tube containing $9.9 \mathrm{ml}$ of $\mathrm{MH}$ broth (Sigma Aldrich, Gillingham, UK) to achieve bacterial concentration of $10^{6} \mathrm{CFU} / \mathrm{ml}$ representing a high microbial load in infected DFUs $[35,36]$. The DL films (6 mm diameter) and filter discs containing $5 \mu \mathrm{g}$ of pure CIP as positive controls were then transferred into the tubes. Tubes containing only bacteria were used as negative controls. The tubes were incubated at $37{ }^{\circ} \mathrm{C}$, with stirring (180 rpm) and aliquots taken at 1.5, 3, 6, 12 and $24 \mathrm{~h}$ and absorbance recorded at $625 \mathrm{~nm}$. In addition, $0.1 \mathrm{ml}$ aliquots were plated directly or after serial 
dilution to count the number of viable bacterial colonies and only plates having 30 to 300 colonies were accepted for determining number of colony forming units/ml (CFU/ml) [37]. For each organism, three replicates $(n=3)$ were carried out.

The antimicrobial activity of the dressings was further evaluated by Kirby-Bauer disk diffusion method. A sterile swab was immersed into the tube containing bacterial suspension $\left(10^{6} \mathrm{CFU} / \mathrm{ml}\right)$ and streaked over $\mathrm{MH}$ agar plates to obtain uniform growth. Circular films (6 $\mathrm{mm}$ diameter) were placed on the colonised agar plates and incubated for $24 \mathrm{~h}$ (at a temperature of $37^{\circ} \mathrm{C}$ ), and then zone of inhibition (ZOI) in mm was subsequently determined with the help of a digital Vernier calliper.

\section{Statistical analysis}

Statistical analysis was undertaking by performing $t$-test and ANOVA) with Microsoft Excel for comparing quantitative data between BLK and DL films, and $p$ values below 0.05 considered as significant.

\section{Results and discussion}

\section{Formulation development and optimisation}

Calcium alginate (CA) is water insoluble but readily dissolves in sodium carbonate solution [18]. The chemistry behind this is that CA forms a gel via ion exchange method, with the divalent calcium ions present in $\beta$-D mannuronic acid (M block) of $\mathrm{CA}$ exchanging with the monovalent sodium ions of the surrounding medium thus forming arranged structures known as an egg box model [38]. The gels were prepared by vortex hydration with heat which helps to quickly hydrate the undissolved polymer, thus preventing lump formation [39]. Heat also helps to reduce the viscosity of the gels, resulting in ease of pouring into the casting containers and also to remove air bubbles entrapped during stirring. Due to gel uniformity (homogeneity), viscosity, absence of lump formation and ease of pouring, 1\% w/w polymer gels were selected and further investigated to improve the transparency and flexibility of the resulting films. The films obtained from gels at concentrations greater than $1 \% \mathrm{w} / \mathrm{w}$ were very hard, brittle, deformed, opaque and inflexible, whereas, films obtained from $0.5 \% \mathrm{w} / \mathrm{w}$ gel were too thin and weak to handle and easily torn. This shows that higher amount of polymer made the films hard and leads to compact structure [40]. However, films obtained from CA- $0.5 \% \mathrm{w} / \mathrm{w}$ gels were more transparent compared to other films obtained from gels with higher amounts of polymer, but with visible calcium carbonate precipitation 
(see XRD discussion below).. Films obtained from $1 \% \mathrm{w} / \mathrm{w}$ gel were less brittle with lower precipitation of calcium carbonate compared to all other films, however, they were less transparent (translucent) as shown in Figure $\mathbf{S 1}$ of the supplementary information.

Further investigation was carried out by dissolving CA in different concentrations of sodium carbonate solution to reduce calcium carbonate precipitation on the film surface. Figure S2 shows that films obtained from CA gels prepared using 0.005-0.011 M sodium carbonate solution were fragile, brittle, deformed, cracked and even more calcium carbonate precipitation. This could be due to the fact that there was not enough sodium ions present. Therefore, the gels were less viscous and evaporated quickly during drying. On the other hand, CA dissolved in $0.028 \mathrm{M}$ sodium carbonate solution resulted in the least brittle film but, precipitation of calcium carbonate was high. CA dissolved in $0.014 \mathrm{M}$ sodium carbonate gave uniform, homogenous and adequate viscous gels, permitting ease of pouring into the Petri dish and resulting in the least precipitation of calcium carbonate among all the films. This could be due to the fact that the ratio between CA and sodium carbonate was optimum for ionic cross-linking, leaving less calcium carbonate residues.

All the unplasticized films did not show the ideal mechanical properties expected of films i.e. durable, soft, flexible, pliable and elastic [33]. To achieve that, the films obtained by dissolving CA in 0.014 M sodium carbonate, were plasticized with different amounts of GLY and digital photographic images are illustrated in Figure S3. Addition of GLY made them more flexible and also improved their transparency. The films plasticized with more than $33.3 \%$ w/w GLY were difficult to remove from the Petri dish owing to strong adhesion as the films became sticky due to the migration of GLY toward the surface, through a leaching phenomenon [38]. However, all plasticized films were transparent which will allow the inspection of the wound bed without the need to remove the dressing. It was observed that films containing GLY at $33.3 \% \mathrm{w} / \mathrm{w}$ (based on total dry weight) were more flexible and tougher than any other plasticized films. The flexibility of the films is important to ensure ease of application to the wound area whilst toughness see tensile data below is important to allow handling as well as resisting the external pressure exerted during body movements around the wounded area. Therefore, the plasticized film containing 33.3\% w/w GLY (CABLK) was selected for drug loading.

The common problem of DL films is the precipitation of drug by recrystallization during film formation as water evaporated from the gel matrix, especially at high drug 
loading [41]. The DL films showed ideal physical appearance as no recrystallized drug was visible to the eye (Figure $\mathbf{S 4})$.

\section{Porosity}

Films are semipermeable in nature and generally appear as continuous sheets of polymer with limited, As shown in Table 1, the unplasticized blank film showed the highest porosity of 56 $\pm 1 \%$ amongst all the formulated films. Addition of GLY decreased porosity because it coated the surface of the films and therefore reduced pore size. The porosity was significantly ( $p=0.0002)$ reduced when the films were plasticized with $33.3 \%$ GLY or above because increased GLY could increase the viscosity of the gels and subsequently yielded more nonporous sheets of polymer. However, incorporation of drug into polymeric matrix (CA film) increased the porosity significantly $(p=0.009)$ when compared to the CA-BLK film (CA$33.3 \%$ GLY). CIP reduced the intermolecular polymer chain interaction and increased void spaces between the polymer chains resulting in higher porosity than the BLK films. Moreover, the porosity was slightly increased with increasing amount of drug into the films.

\section{Water absorption $(A w)$ and equilibrium water content (EWC)}

The Aw and EWC are two functional properties that impact upon absorption of exudates at reasonably rapid rates. EWC and Aw of the films gradually decreased with increasing GLY content as shown in Table 1. The unplasticized films showed the highest EWC and Aw of $79 \pm 1 \%$ and $380 \pm 12 \%$ respectively whereas films plasticized with $50 \%$ w/w GLY showed the lowest EWC and Aw of $66 \pm 1 \%$ and $193 \pm 5 \%$ respectively. This could be attributed to the porosity of the dressings where addition of GLY decreased their porosity (see Table 1) and therefore, decreased the EWC and Aw. The DL films showed a higher EWC and Aw compared to CA-BLK films. The values of EWC and Aw of CA-BLK film increased from $74 \pm 1 \%$ to $77 \pm 1 \%$ and $282 \pm 8 \%$ to $328 \pm 25$ respectively; after loading drug. This is also due to increase in porosity of the DL films which enabled ingress and retention of more fluid within the swollen film matrix.

\section{Water vapour transmission rate}

DL films exhibited higher WVTR values (Table 1) ranging from $3257 \pm 172$ to $3877 \pm 196$ $\mathrm{g} / \mathrm{m}^{2} \mathrm{day}^{-1}$ than the films without drug $(2687-3682)$. This is because; addition of drug 
increases the intermolecular chain mobility, resulting in increased porosity which allows higher diffusion of water molecules through the films matrix. High WVTR will prevent excess accumulation of wound exudates and subsequently prevent maceration of surrounding healthy skin. The WVTR values of DL films are ideal considering the amount of exudate produced by patients with chronic leg ulcers per day $\left(5 \mathrm{~g} / 10 \mathrm{~cm}^{2} \sim 5000 \mathrm{~g} / \mathrm{m}^{2}\right)$ [42]. Therefore, the DL films will absorb about $65-77 \%$ fluid from full-thickness chronic wound bed whilst also maintaining a moist environment to facilitate wound healing.

\section{Swelling index}

The swelling behaviour of the films was evaluated in SWF ( $\mathrm{pH} 7.4$ ) and the effect of GLY and drug was also investigated (Figure 1). The unplasticized film (1\% CA-0.0\% GLY) showed the highest swelling index ranging from $453 \pm 35 \%$ to $434 \pm 22 \%$ over $60 \mathrm{~min}$, while film plasticized with 50\% GLY showed the lowest swelling index ranging between $206 \pm 2 \%$ and $197 \pm 3 \%$.

The addition of GLY reduced swelling capacity because of the reduction in porosity as well as its humectant properties [43]. As porosity decreases, water ingress into the matrix also decreases resulting in reduced initial hydration and subsequent swelling. Moreover, GLY is already rich in moisture, so it does not allow absorption of high amounts of moisture, however, the plasticized film dressings can provide moisture in dry wounds to avoid wound desiccation. The film containing 33.3\% GLY showed swelling capacity value ranging from $299 \pm 7 \%$ to $284 \pm 8 \%$ over $60 \mathrm{~min}$. After loading drug into this film, the swelling capacity did not change in a significant way. However, the plasticised (1\% CA-33.3\% GLY) film containing $0.005 \%$ drug showed the lowest swelling capacity amongst the DL films, with values ranging from $231 \pm 17 \%$ to $229 \pm 7 \%$ over $60 \mathrm{~min}$. This could be due to the fact that the film containing $0.005 \%$ CIP was more rigid (also confirmed by texture analysis, Figure 2a) than other DL films which resulted in lower porosity (Table 1) and therefore lower rate of water intake. It can also be observed that all films maintained steady swelling after 15 min.

\section{Evaporative water loss (EWL)}

The EWL indicates moisture loss behaviour of the dressings when exposed to air. All the films exhibited water loss of about $50 \%$ within half an hour, indicating that generally, the dressings can lose water quickly when they come into contact with air. After $1.5 \mathrm{~h}$ the water 
loss from unplasticized, plasticized and $0.010 \%$ DL films was not significant $(p=0.78)$ and retained 17-20\% of water after 24 h (Figure S5 of supplementary information,). However, films containing $0.005 \%$ and $0.025 \%$ CIP acquired steady water content within $5 \mathrm{~h}$ and retained $13-11 \%$ water after $24 \mathrm{~h}$. The fast water loss and low amount of water remaining within the matrix indicates that the films will be highly effective in highly exuding chronic wounds such as DFUs as it will enable the dressings to imbibe enough exudates from the wound bed by an active upward diffusion process to avoid excess accumulation of exudate underneath the dressing.

\section{Moisture content}

Thermogravimetric analysis detected the residual water content of the formulated films. The uplasticized film showed residual moisture content of about $5 \pm 1 \%$ which increased up to $8 \pm$ $0 \%$ after addition of GLY. The increase is due to the hydrophilicity and strong humectant properties of GLY. Since GLY is highly hydrophilic, the content of GLY in the films resulted in higher amounts of bound water and therefore enhancing residual moisture content [44]. After loading CIP, the residual moisture content was further increased to about $11 \pm 0 \%$ because of increase in porosity which enabled it to absorb more moisture. It could also be observed that the incorporation of drug increased hydrophilicity of the polymeric matrix resulting in higher amounts of bound water and therefore increased residual moisture content. However, high enough residual water within the dressings can keep the wound and surrounding normal skin in an ideal state of hydration, implying that the dressings are expected to perform effectively when compressed during application [45].

\section{Texture analysis}

The DL plasticized films, BLK plasticized films and BLK unplasticised films were tested by texture analyser for tensile strength (brittleness), elasticity (\% elongation at break) and elastic modulus (rigidity) and adhesion properties to understand the effects of drug loading and plasticizer on the polymeric matrix. 
Mechanical (tensile) properties of films

The ideal film dressing should be flexible, durable, soft, elastic, pliable and stress resistant against different parts of the body during application. Texture analysis was used to investigate whether the formulated film dressings possessed these ideal mechanical properties. The clear correlation between GLY content and the mechanical properties of films were observed with unplasticized films being too brittle (Figure S1: CA-1.0\% w/w) and failed during texture analysis. The tensile strength of the plasticized films increased with addition of GLY up to $33.3 \%$. The values ranged from $5 \pm 1 \mathrm{~N} / \mathrm{mm}^{2}$ to $15 \pm 2 \mathrm{~N} / \mathrm{mm}^{2}$ as shown in Figure 2a. However, addition of higher amounts of GLY (42.8 and $50.0 \%$ ) resulted in a lowering of tensile strength $\left(9 \pm 1 \mathrm{~N} / \mathrm{mm}^{2}\right.$ and $\left.7 \pm 1 \mathrm{~N} / \mathrm{mm}^{2}\right)$. The decrease in tensile strength at higher GLY content might be due to leaching phenomena with significant reduction of intermolecular and intramolecular bonding in the CA network.

Further, investigations were undertaken by measuring Young's (elastic) modulus and elongation at break to optimise GLY content for DL films. Young's modulus was estimated from the slope of the initial linear portion of stress-strain curve. Figure 2a shows that the Young's modulus increases gradually with increasing GLY and after certain GLY content it decreased as was the case with tensile strength values. The maximum Young's modulus (78 \pm $9 \mathrm{MPa}$ ) was achieved at a GLY concentration of $33.3 \% \mathrm{w} / \mathrm{w}$. Figure $2 \mathbf{a}$ also illustrates the effect of GLY on the films elongation which increased with increasing GLY content. This is because addition of GLY increased the number of $-\mathrm{OH}$ groups resulting in weak hydrogen bonding within CA. The intermolecular force decreased resulting in increased mobility caused by enlarged spaces between polymeric chains and subsequent increase in percentage elongation at break. A sharp rise in elongation can be observed in Figure 2a when the concentration of GLY was above $33.3 \% \mathrm{w} / \mathrm{w}$ in the gel. The significant $(p=0.002)$ increase in elongation corresponded to a decrease in Young's modulus.

The above mechanical properties, confirmed the selection of films containing $33.3 \%$ w/w of GLY for drug loading. As shown in Figure 2a, the differences in tensile strength and percentage elongation of films containing $0.005 \%$ CIP were insignificant $(p=0.84 \& p=$ 0.07) when compared to BLK film. However, Young's modulus was significantly ( $p=0.01)$ decreased after loading drug. Films loaded with more than $0.005 \%$ CIP were highly brittle as evidenced by having the lowest elongation $(4 \pm 2 \%)$. None of the DL films and CA-BLK showed ideal values (30-50\%) of elasticity [46]. However, the Young's modulus and tensile 
strength values showed the film containing $0.005 \%$ CIP was not too brittle and this was confirmed during handling of this film. Moreover, all the values of mechanical properties were decreased with increasing concentration of drug that indicated low drug loading capacity of the CA based films, usually attributed to the reduced physical volume available for drug distribution. The mechanical tensile behaviour of CA films depend on the source and extraction treatment, and ratio of guluronic and mannuronic acid of the polymer [47]. The mechanical properties of films can be improved by combining the polymer with either natural or synthetic polymers as reported by Boateng and co-workers $[33,39,48]$.

In-vitro adhesion studies

As shown in Figure 2b, the stickiness of the films increased with increasing GLY content in the presence of SWF containing $2 \% \mathrm{w} / \mathrm{w} \mathrm{BSA}$. This could be explained by the fact that GLY enhances the hydrogen bonding between the polymeric chain and model wound surface and therefore increases adhesion properties. Furthermore, GLY acts as a humectant that promotes initial hydration in the presence of SWF which consequently imparts the increased stickiness. The stickiness of DL dressings also did not change when compared to the BLK film (1\% CA-33.3\% GLY). Figure $2 \mathbf{b}$ also shows the WOA and cohesiveness of the films. Cohesiveness means ability to resist the detachment from model wound surface, whereas WOA represents the total energy required to separate the probe from the wound surface. The cohesiveness of the films containing 0.005 and $0.010 \%$ CIP was significantly ( $p$ $=0.001$ ) increased compared to all other formulations. The value increased from $1.07 \pm 0.24$ $\mathrm{mm}$ to $7.02 \pm 0.24 \mathrm{~mm}$ indicating that the films containing 0.005 and $0.001 \% \mathrm{CIP}$ will adhere onto the wound surface better. Films loaded with $0.025 \%$ CIP showed low cohesiveness of about $2.05 \pm 0.43 \mathrm{~mm}$ which can be attributed to poor mechanical properties in terms of Young's modulus, elongation and tensile strength. The WOA slightly increased with increasing drug concentration. However, the values for $0.005,0.010$ and $0.025 \%$ CIP loaded films $(0.94 \pm 0.29,1.44 \pm 0.35$ and $1.40 \pm 0.56$ N.mm respectively) did not exceed the value $(1.47 \pm 0.31 \mathrm{~N} . \mathrm{mm})$ for BLK film and there was no significant difference $(p=0.6)$ in WOA between BLK and DL films. 
The FTIR spectra of different starting materials (CIP, GLY and CA) and DL dressings are shown in Figure 3. Some of the characteristic peaks from CIP such as aryl fluoride (at $1050 \mathrm{~cm}^{-1}$ ), carbonyl group (at $1450 \mathrm{~cm}^{-1}$ ) and quinolones (at $1650 \mathrm{~cm}^{-1}$ ) were invisible in the spectra of DL dressings. This might be due to the fact that the relatively low amounts of CIP incorporated were suppressed by the higher amounts of polymer and plasticizer that prevented them from being visible in the spectra. This also suggests the possible molecular dispersion of drug into the polymeric matrix. Pure CA showed the broad peak of $\mathrm{OH}$ stretching at $3204 \mathrm{~cm}^{-1}$ and this peak became broader (band between 3045 and $3600 \mathrm{~cm}^{-1}$ ) and less intense (confirmed by IR imaging, Table S1) after loading drug. This could be explained by the fact that incorporation of drug into polymeric gel promoted interaction of fluorine, carbonyl and amine (-NH) of CIP with hydrogen atom of CA resulting in shorter distance between the drug molecules and $\mathrm{OH}$ group of $\mathrm{CA}$ and therefore, broadened the peak with lower intensity. Lower intensity might also be related to decreased crystallinity of the DL films confirmed by XRD and SEM. A band appeared at $874 \mathrm{~cm}^{-1}$ for $\beta-\mathrm{C} 1-\mathrm{H}$ deformation vibration and at $947 \mathrm{~cm}^{-1}$ for $\mathrm{C}-\mathrm{O}$ stretching vibration of uronic acid and $\mathrm{C}-\mathrm{C}-\mathrm{H}$ and $\mathrm{C}-\mathrm{O}-\mathrm{H}$ deformation. The peak at $1025 \mathrm{~cm}^{-1}$ was for the C-O-C for antisymmetric stretching vibration of pyranosyl ring. This peak was stronger in the pure polymer than the DL films as red domains appeared more in pure CA and gradually changed to blue in DL films. Further, another two peaks can be seen at 1411 and $1591 \mathrm{~cm}^{-1}$ for the symmetric and asymmetric stretching of carboxylate ion (-COO-) respectively. Most of the peaks of CA-BLK (1\% CA$33.3 \%$ GLY) and DL loaded dressings were similar to the pure polymer but different in intensity and also confirmed by IR imaging (Table S1). Different intensities of the bands indicate the uniform distribution of the polymer and the drug, and homogeneity of films $[49,50]$. The overlay plot (data not shown) of the spectral profiles of the films from different collection points $(10 \times 7)$ also confirmed uniform chemical distribution of the materials.

\section{Scanning electron microscopy}

From Figure 4 it can be observed that the surface of the films was generally not smooth possibly due to calcium carbonate precipitation in the formulations as the films dried and this was also confirmed by XRD (Figure S6). However, the plasticized films appeared smoother than the unplasticized film (CA-0.0\% GLY). This indicates that addition of GLY 
largely improves the homogeneity of the CA films by reducing or masking calcium carbonate precipitation with decrease in the crystallinity on the surface as the amount of GLY increased. This is because the hydroxyl groups in GLY penetrated into the polymeric matrix and formed hydrogen bonds with hydroxyl groups of CA thus creating large spaces between the polymeric chains, resulting in reduced surface crystallinity [47]. However, presence of calcium carbonate did nus affect the homogeneous üsuivution of the drug throughout the films confirmed by drug content uniformity test (Table S2). Further, it has been reported that calcium carbonate is good for bone regeneration [51] and also possessing antibacterial activity [52]. Therefore, presence of some amount of residual calcium carbonate will be expected to play a partial role in the closure (healing) of DFUs.

The DL films showed (Figure 4) a smoother surface morphology compared to CABLK film.. This be due to the fact that, after adding CIP, the number of hydroxyl groups increased, thus enhancing interaction between the CIP molecules, and the polymer, and therefore promoting intermolecular hydrogen bonding. This helped to increase the spaces between the crystal lattice and engulfed the residual calcium carbonate and thereby decreased the overall crystallinity of the DL films.

\section{In-vitro drug dissolution studies}

The drug loading efficiency determined for films containing $0.005,0.010$ and $0.025 \%$ CIP was $65.81 \pm 3.98 \%, 60.99 \pm 2.01 \%$ and $55.01 \pm 4.27 \%$ respectively, which appeared relatively low. This could be explained by the fact that the drying process during film formation results in a dense and very thin product resulting in precipitation of excess drug on the surface of the films some of which can be lost through scraping and contact during handling [53]. Moreover, it also reveals that higher amounts of drug originally added into the dressings resulted in decreasing loading efficiency into the dressing matrix. The drug content uniformity was also investigated to check the homogeneous distribution of the drug all over the dressings. The HPLC analysis from three different locations of the dressings confirmed that there was no statistically significant difference (Table S2) in drug content. In addition, the distribution of drug was also be confirmed by antibacterial study of testing ZOI see below as well as IR mapping (Table S1). 
The drug release profiles closely matched the swelling (Figure 1) of the films. A quick hydration of the dressings was observed within 15 min and within this time more than $50 \%$ drug was released. This means films containing $0.005 \%$ and $0.010 \%$ CIP can reach MBC (99.9\% inhibition) to eradicate E. coli and P. aeruginosa within that time. In the case of films containing $0.025 \% \mathrm{CIP}$ is expected to achieve MBC for killing all three organisms (E. coli, P. aeruginosa and $S$. aureus) within $5 \mathrm{~min}$. The films exhibited maximum drug release within $45 \mathrm{~min}$ about $90.50 \pm 3.93 \%, 91.18 \pm 7.44 \%$ and $100.41 \pm 11.15 \%$ respectively (Figure 5). This indicates that the release of CIP from the film dressings could potentially reduce microbial load very quickly, which is important in highly infected chronic wounds such as DFUs where the bacteria load needs to be significantly reduced to allow wound healing to progress beyond the inflammatory phase.

\section{Drug release kinetics}

CIP loaded films showed diverse release profiles, evaluated by model dependant equations such as Higuchi, Korsmeyer-Peppas, zero order and first order [34]. All data obtained from those mathematical equations are summarized in Table S3. It can be observed from Table S3 that release of CIP from the films followed first order release mechanism in which release rate depends on the concentration of drug. Figure 5 also supports this kinetic mechanism of drug release where the highest amount of drug $(0.025 \% \mathrm{w} / \mathrm{v})$ loaded film released maximum drug within $45 \mathrm{~min}$. For a better understanding of drug release mechanism, the diffusion exponent (n) values from the Korsmeyer-Peppas equation, were calculated and fell within the range of 0.54-0.59. This suggested CIP was released from the films by anomalous transport, which implies that the release of CIP from the hydrated polymer combined gel erosion and diffusion of the drug through the swollen gel.

\section{MTT (cell viability) assay}

Cytotoxicity test is vital when chemicals and devices such as drug loaded dressings, are likely to come into contact with the wounded skin as well as normal skin. The CIP loaded film dressings were applied to human primary epidermal keratinocyte (PEK) cell lines, representing wounded skin. MTT assay revealed that the polymer (CA) used in this study was non-toxic to human keratinocyte cells. The BLK film showed about $88.3 \pm 1.0 \%$ cell viability over $72 \mathrm{~h}$ (Figure 6). All DL dressings showed more than $80 \%$ cell viability over $72 \mathrm{~h}$ which 
are acceptable according to International Organization for Standardization (DIN EN ISO 10993-5). Time dependent cell viability of PEK was also observed when treated with DL films. Triton-X-100 (positive control) killed all cells compared to untreated cells (negative control) after $72 \mathrm{~h}$ of exposure. Additionally, the keratinocytes were observed microscopically before and after treatment with the samples. In the case of DL dressings, the viable cells appeared as polygonal structures adhered to the well plates (image not shown). Very few dead non adherent cells were observed after treating with the dressings, whereas most of the cells were floating when treated with Triton-X-100. There was no reduction of adherent cell numbers in untreated cells. These observations further confirm the non-toxic nature of the drug loaded dressings compared to the known toxic Triton-X-100.

\section{Antibacterial Study}

The absorbance readings measured showed significant difference $(p=0.001)$ between E. coli, S. aureus and P. aeruginosa incubated with BLK and CIP loaded films (Figure S7. ac). Clear bacterial suspensions also showed that the released antibiotic was effective in eradication of the bacterial load (Figure S7 (a-c), whilst BLK films showed no antibacterial effects, confirming the ZOI assay below (Figure S8). The optical density (OD) values of the negative control containing only bacteria and the -BLK films gradually increased over time. However, the DL films showed values below 0.25 throughout the period of incubation. The low OD values of DL dressings was due to decreased turbidity because of bacterial eradication, and was confirmed by the time kill assay. Figure 7 illustrates the rate of bacterial $\left(10^{6} \mathrm{CFU} / \mathrm{ml}\right.$ representing chronic wounds) eradication when treated with DL films. Pure CIP (positive control) and film containing $0.025 \%$ CIP (w/v) completely killed E. coli after 1.5 and $3 \mathrm{~h}$ respectively. Complete eradication of $E$. coli by films containing $0.005 \%$ and $0.010 \%$ CIP (w/v) was observed at 24 h. S. aureus is the most common infection causative bacteria present in DFUs, however, all viable cells of $S$. aureus were killed by the DL films within 24 h. The complete eradication of $P$. aeruginosa was also observed after $24 \mathrm{~h}$ of treatment. The tube containing only bacteria (negative control) showed an increase in cell count confirming the importance of rapid eradication of bacterial cells to prevent infection progression. It was also noticed that all DL films exhibited maximum bactericidal effect $(99.9 \%$ reduction of bacterial cells) within $1.5 \mathrm{~h}$ which correlates well with the in vitro drug release data. 
Zone of inhibition (ZOI) of the positive control (pure CIP) were 37 $\pm 1,28 \pm 1$ and 34 \pm 1 against E. coli, S. aureus and $P$. aeruginosa respectively (Figure S8 and Table S4). According to reported standard guidelines, in disk diffusion technique, $5 \mu \mathrm{g}$ CIP should have ZOI of 30-40, 22-30 and 25-33 mm against E. coli, S. aureus and P. aeruginosa respectively [54]. CIP loaded films showed ZOI of 34-38, 27-32 and 29-33 mm against E. coli, S. aureus and $P$. aeruginosa respectively (Table S4), therefore this experiment achieved this standardization. In addition, the average ZOI for E. coli, S. aureus and P. aeruginosa increased as the CIP content increased within the dressings. Clear ZOIs were observed (Figure S8) in DL films for both Gram-positive and Gram-negative bacteria, however, BLK films showed no ZOI against all the three bacteria tested, which confirmed that the CA on its own did not possess any antibacterial activity.

\section{Conclusions}

The films plasticised with $33.3 \% \mathrm{w} / \mathrm{w}$ GLY were soft, flexible, pliable and transperant and drug incorporation did not affect the transperency indicating uniform drug distribution without significant precipitation which was confirmed by SEM, XRD, FTIR, IR mapping and drug content uniformity studies. The dressings exhibited potential tensile and bio-adhesive properties required for easy application and to ensure adherence to the wound bed. The DL films showed higher Aw $(328 \pm 25)$ and EWC $(77 \pm 1)$ than the BLK films, influenced by their differences in porosity, however, their swelling index values were similar. The high WVTR (maximum $3877 \pm 196 \mathrm{~g} / \mathrm{m}^{2} \mathrm{day}^{-1}$ ) and EWL (50\% within half an hour) indicate that the films will remove exudates from the wound bed through the polymer swollen matrix into the surrounding environment rapidly. The films exhibited maximum drug release (> 90\%) within 45 min which will provide enough drug concentration to reduce bacterial load before the next change of the dressing. Complete eradication of all causative bacteria were observed after $24 \mathrm{~h}$ which will be very effective to prevent infection progression in DFUs. The dressings showed more than $80 \%$ cell viability of PEK over $72 \mathrm{~h}$ which confirmed their safety for patients. Although CA antimicrobial film dressings exhibited promising characteristics for wound healing, in vivo wound healing study will need to be undertaken in the future to confirm its effectiveness. 


\section{Future Perspective}

In the next five to ten years, interest in advanced bioactive medicated dressings such as ciprofloxacin loaded alginate films, which take an active part in the wound healing process, will continue to grow. This will be driven by the need for more effective but affordable therapies that will shorten the treatment regime and reduce the chances of hospital acquired resistant bacterial infections, which are a common cause of amputations and mortality in DFU patients. Broad spectrum antibiotic loaded dressings comprising well established bioactive polymers such as alginate will probably compliment the silver based antibacterial dressings currently on the market to increase the chances of fully arresting the scourge of chronic ulcers caused by prolonged infection.

\section{Financial \& competing interests disclosure}

The authors have no relevant affiliations or financial involvement with any organization or entity with a financial interest in or financial conflict with the subject matter or materials discussed in the manuscript. This includes employment, consultancies, honoraria, stock ownership or options, expert testimony, grants or patents received or pending, or royalties.

No writing assistance was utilized in the production of this manuscript.

\section{Executive Summary}

$>$ Alginate film dressings were successfully prepared from CA by ion exchange method and transparent and flexible films were obtained by adding GLY as a plasticizer.

$>$ The formulated films showed ideal fluid handling properties in terms of Aw, EWC, swelling index, WVTR and EWL.

Uniform distribution of drug and polymer within the film matrix was confirmed by IR imaging and drug content uniformity test, indicating that the film can be cut to the desired size and will work effectively due to proper distribution of drug and polymer.

$>$ The quick release of CIP from the dressings can ensure rapid eradication of both Gram positive and Gram negative bacteria, to reduce deterioration of chronic DFUs and enhance healing times.

$>$ The most prevalent bacteria present in DFUs were completely killed within $24 \mathrm{~h}$ of treatment while testing in-vitro. 
The formulated film showed high biocompatibility with the human primary epidermal keratinocytes cells indicating that the films will safe for both healthy skin and newly formed tissue in the wounded area.

\section{References}

1 Posnett J, P.J.F. The burden of chronic wounds in the UK. Nurs Times. 104(January 2008), 44-45 (2008).

2 Kerr M. Diabetic Foot Care in England: an Economic Study. Insight Heal Econ. (2017). https://www.diabetes.org.uk/Upload/Shared practice/Diabetic footcare in England, An economic case study (January 2017).pdf.

3 Dowsett C, Bielby A, Searle R. Reconciling increasing wound care demands with available resources. $J$ Wound Care. 23(11), 552-562 (2014).

4 HM Treasury. Public Expenditure Statistical Analyses 2016. (2016).

https://www.gov.uk/government/statistics/public-expenditure-statistical-analyses2016\#history.

5 Healthcare Quality Improvement Partnership. National Diabetes Foot Care Audit Report (2014 - 2016). (2017).

http://www.content.digital.nhs.uk/catalogue/PUB23525/nati-diab-foot-care-audit-1416-rep.pdf.

6 Kavitha KV, Tiwari S, Purandare VB, Khedkar S, Bhosale SS, Unnikrishnan AG.

Choice of wound care in diabetic foot ulcer: A practical approach. World J Diabetes. 5(4), 546-556 (2014).

7 Abdulrazak A, Ibrahim Bitar Z, Ayesh Al-Shamali A, Ahmed Mobasher L.

Bacteriological study of diabetic foot infections. J Diabetes Complications. 19(3), 38$141(2005)$.

8 Tiwari S, Pratyush DD, Dwivedi A, Gupta SK, Rai M, Singh SK. Microbiological and clinical characteristics of diabetic foot infections in northern India. J Infect Dev Ctries. 6(4), 329-332 (2012).

9 Shanmugam P, M J, Susan SL. The bacteriology of diabetic foot ulcers, with a special 
reference to multidrug resistant strains. J Clin Diagn Res. 7(3), 441-445 (2013).

10 Chita T, Muntean D, Baditoiu L, et al. Staphylococcus aureus strains isolated from diabetic foot ulcers. Identification of the antibiotic resistant phenotypes. Rom J Diabetes Nutr Metab Dis. 20(4), 389-393 (2013).

11 Morales JO, McConville JT. Manufacture and characterization of mucoadhesive buccal films. Eur J Pharm Biopharm. 77(2), 187-199 (2011).

12 Kumar S, Gupta SK, Sharma PK. A Review on Recent Trends in Oral Drug DeliveryFast Dissolving Formulation Technology. Adv Biol Res (Rennes). 6(1), 6-13 (2012).

13 Sarheed O, Ahmed A, Shouqair D, Boateng J. Antimicrobial Dressings for Improving Wound Healing. Wound Healing - New insights into Ancient Challenges, Dr. Vlad Alexandrescu (Ed.). InTech. 2016 (October), 377-402 (2016).

https://www.intechopen.com/books/wound-healing-new-insights-into-ancientchallenges/antimicrobial-dressings-for-improving-wound-healing.

14 Sood A, Granick MS, Tomaselli NL. Wound Dressings and Comparative Effectiveness Data. Adv wound care. 3(8), 511-529 (2014).

15 Rubio PA. Use of semiocclusive, transparent film dressings for surgical wound protection: Experience in 3637 cases. Int Surg. 76(4), 253-254 (1991).

16 Mayet N, Choonara YE, Kumar P, et al. A comprehensive review of advanced biopolymeric wound healing systems. J Pharm Sci. 103(8), 2211-2230 (2014).

17 Momoh FU, Boateng JS, Richardson SCW, Chowdhry BZ, Mitchell JC. Development and functional characterization of alginate dressing as potential protein delivery system for wound healing. Int J Biol Macromol. 81, 137-150 (2015).

18 Tarun K, Gobi N. Calcium alginate/PVA blended nano fibre matrix for wound dressing. Indian J Fibre Text Res. 37(2), 127-132 (2012).

19 Taskin AK, Yasar M, Ozaydin I, et al. The hemostatic effect of calcium alginate in experimental splenic injury model. Ulus Travma Acil Cerrahi Derg. 19(3),195-199 (2013).

20 Hilton JR, Williams DT, Beuker B, Miller DR, Harding KG. Wound dressings in 
diabetic foot disease. Clin Infect Dis. 39(Suppl 2), 100-103 (2004).

21 Jannesari M, Varshosaz J, Morshed M, Zamani M. Composite poly(vinyl alcohol)/poly(vinyl acetate) electrospun nanofibrous mats as a novel wound dressing matrix for controlled release of drugs. Int J Nanomedicine. 6, 993-1003 (2011).

22 Okoye EI, Okolie TA. Development and in vitro characterization of ciprofloxacin loaded polymeric films for wound dressing. Int J Health Allied Sci. 4(4), 234-242 (2015).

23 Puoci F, Piangiolino C, Givigliano F, et al. Ciprofloxacin-collagen conjugate in the wound healing treatment. J Funct Biomater. 3(2), 361-371 (2012).

24 Andrews JM. Determination of minimum inhibitory concentrations. J Antimic Chemother. 48(Suppl 1), 5-16 (2001).

25 Lebel M. Ciprofloxacin: Chemistry, Mechanism of Action, Resistance, Antimicrobial Spectrum, Pharmacokinetics, Clinical Trials, and Adverse Reactions.

Pharmacotherapy. 8(1), 3-33 (1988).

26 Dong Z, Wang Q, Du Y. Alginate/gelatin blend films and their properties for drug controlled release. J. Memb. Sci. 280(1-2), 37-44 (2006).

27 Öztürk E, Agalar C, Keçeci K, Denkbaş EB. Preparation and characterization of ciprofloxacin-loaded alginate/chitosan sponge as a wound dressing material. J. Appl. Polym. Sci. 101(3), 1602-1609 (2006).

28 Kataria K, Gupta A, Rath G, Mathur RB, Dhakate SR. In vivo wound healing performance of drug loaded electrospun composite nanofibers transdermal patch. Int. J. Pharm. 469(1), 102-110 (2014).

29 Roy DC, Tomblyn S, Burmeister DM, et al. Ciprofloxacin-Loaded Keratin Hydrogels Prevent Pseudomonas aeruginosa Infection and Support Healing in a Porcine FullThickness Excisional Wound. Adv Wound Care. 4(8), 457-468 (2015).

30 Catanzano O, Docking R, Schofield P, Boateng J. Advanced multi-targeted composite biomaterial dressing for pain and infection control in chronic leg ulcers. Carbohydr Polym. 172, 40-48 (2017).

31 Guan J, Fujimoto KL, Sacks MS, Wagner WR. Preparation and characterization of highly porous, biodegradable polyurethane scaffolds for soft tissue applications. Biomaterials. 26(18), 3961-3971 (2005).

32 Zhang Y, Zhang M. Microstructural and mechanical characterization of chitosan 
scaffolds reinforced by calcium phosphates. J Non Cryst Solids. 282(2-3), 159-164 (2001).

33 Boateng JS, Pawar H V., Tetteh J. Polyox and carrageenan based composite film dressing containing anti-microbial and anti-inflammatory drugs for effective wound healing. Int J Pharm. 441(1-2), 181-191 (2013).

34 Boateng JS, Matthews KH, Auffret AD, Humphrey MJ, Stevens HN, Eccleston GM. In vitro drug release studies of polymeric freeze-dried wafers and solvent-cast films using paracetamol as a model soluble drug. Int J Pharm. 378(1-2), 66-72 (2009).

35 Anisha BS, Biswas R, Chennazhi KP, Jayakumar R. Chitosan-hyaluronic acid/nano silver composite sponges for drug resistant bacteria infected diabetic wounds. Int J Biol Macromol. 62, 310-320 (2013).

36 Unnithan AR, Barakat NAM, Tirupathi Pichiah PB, et al. Wound-dressing materials with antibacterial activity from electrospun polyurethane-dextran nanofiber mats containing ciprofloxacin HCl. Carbohydr Polym. 90(4), 1786-1793 (2012).

37 Ong SY, Wu J, Moochhala SM, Tan MH, Lu J. Development of a chitosan-based wound dressing with improved hemostatic and antimicrobial properties. Biomaterials. 29(32), 4323-4332 (2008).

38 Lee KY, Mooney DJ. Alginate: Properties and biomedical applications. Prog Polym Sci. 37(1), 106-126 (2012).

39 Boateng JS, Stevens HN, Eccleston GM, Auffret AD, Humphrey MJ, Matthews KH. Development and mechanical characterization of solvent-cast polymeric films as potential drug delivery systems to mucosal surfaces. Drug Dev Ind Pharm. 35(8), 986996 (2009).

40 Boateng JS, Auffret AD, Matthews KH, Humphrey MJ, Stevens HNE, Eccleston GM. Characterisation of freeze-dried wafers and solvent evaporated films as potential drug delivery systems to mucosal surfaces. Int J Pharm. 389(1-2), 24-31 (2010).

41 Boateng J, Mani J, Kianfar F. Improving drug loading of mucosal solvent cast films using a combination of hydrophilic polymers with amoxicillin and paracetamol as model drugs. Biomed Res Int. 2013,1-8 (2013). 
42 Thomas S. Fluid Handling Properties of Allevyn Dressing. Wound Management Communication. (2007). http://www.dressings.org/TechnicalPublications/PDF/S+NAllevyn-March-2007/Allevyn-Fluid-Handling-Properties-April-2007.pdf.

43 Stout EI, McKessor A. Glycerin-Based Hydrogel for Infection Control. Adv wound care. 1(1), 48-51 (2012).

44 Rhim JW, Gennadios A, Weller CL, Hanna MA. Sodium dodecyl sulfate treatment improves properties of cast films from soy protein isolate. Ind Crops Prod. 15(3), 199205 (2002).

45 Thomas $\mathrm{S}$. The role of dressings in the treatment of moisture-related skin damage. World Wide Wounds. (2008).

http://www.worldwidewounds.com/2008/march/Thomas/Maceration-and-the-role-ofdressings.html.

46 Boateng JS, Popescu AM. Composite bi-layered erodible films for potential ocular drug delivery. Colloids Surfaces B Biointerfaces. 145, 353-361 (2016).

47 Gao C, Pollet E, Avérous L. Properties of glycerol-plasticized alginate films obtained by thermo-mechanical mixing. Food Hydrocoll. 63, 414-420 (2017).

48 Pawar HV, Tetteh J, Boateng JS. Preparation, optimisation and characterisation of novel wound healing film dressings loaded with streptomycin and diclofenac. Colloids Surfaces B Biointerfaces. 102, 102-110 (2013).

49 Limban C, Missir AV, Grumezescu AM, et al. Bioevaluation of novel anti-biofilm coatings based on PVP/Fe $3 \mathrm{O} 4$ nanostructures and 2-((4-Ethylphenoxy)methyl)-N(arylcarbamothioyl)benzamides. Molecules. 19(8), 12011-12030 (2014).

50 Hifumi H, Ewing A V., Kazarian SG. ATR-FTIR spectroscopic imaging to study the drying and dissolution of pharmaceutical polymer-based films. Int. J. Pharm. 515(12), 57-68 (2016).

51 Fujihara K, Kotaki M, Ramakrishna S. Guided bone regeneration membrane made of polycaprolactone/calcium carbonate composite nano-fibers. Biomaterials. 26(19), 4139-4147 (2005).

52 Ataee RA, Derakhshanpour J, A MT, Eydi A. Antibacterial effect of Agrobacterium tumefaciens calcium carbonate nanoparticles on Agrobacterium tumefaciens. 13(2), 65-70 (2011). 
53 Boateng JS, Matthews KH, Auffret AD, Humphrey MJ, Eccleston GM, Stevens HN. Comparison of the in vitro release characteristics of mucosal freeze-dried wafers and solvent-cast films containing an insoluble drug. Drug Dev Ind Pharm. 38(1), 47-54 (2012).

54 CIPRO ${ }^{\circledR}$ (ciprofloxacin hydrochloride) TABLETS CIPRO ${ }^{\circledR}$ (ciprofloxacin*) ORAL SUSPENSION. Bayer HealthCare.(2004).

https://www.accessdata.fda.gov/drugsatfda_docs/label/2004/19537s049,19857s031,19 847se5-027,20780se5-013_cipro_lbl.pdf. 
Table 1 The porosity, EWC, Aw, WVTR and moisture content, of different film formulations $(n=3 \pm \mathrm{SD})$.

\begin{tabular}{|c|c|c|c|c|c|}
\hline Films & $\begin{array}{c}\text { Porosity } \\
(\%)\end{array}$ & EWC (\%) & Aw (\%) & WVTR $\left(g / m^{2}\right.$ day $\left.^{-1}\right)$ & $\begin{array}{c}\text { Moisture } \\
\text { content (\%) }\end{array}$ \\
\hline $1 \%$ CA-0.0\% GLY & $56 \pm 1$ & $79 \pm 1$ & $380 \pm 12$ & $3185 \pm 739$ & $5 \pm 1$ \\
\hline 1\% CA-9.1\% GLY & $55 \pm 5$ & $79 \pm 0$ & $379 \pm 6$ & $3450 \pm 417$ & $8 \pm 0$ \\
\hline 1\% CA-20.0\% GLY & $51 \pm 3$ & $75 \pm 1$ & $309 \pm 17$ & $26870 \pm 226$ & $7 \pm 1$ \\
\hline 1\% CA-33.3\% GLY & $38 \pm 4$ & $74 \pm 1$ & $282 \pm 8$ & $2919 \pm 224$ & $8 \pm 1$ \\
\hline $1 \%$ CA-42.8\% GLY & $34 \pm 4$ & $70 \pm 1$ & $239 \pm 6$ & $3483 \pm 9$ & $8 \pm 0$ \\
\hline 1\%CA-50.0\% GLY & $30 \pm 2$ & $66 \pm 1$ & $193 \pm 5$ & $3682 \pm 215$ & $8 \pm 0$ \\
\hline 1\% CA-0.005\% CIP & $46 \pm 6$ & $74 \pm 1$ & $287 \pm 7$ & $3809 \pm 48$ & $11 \pm 0$ \\
\hline 1\% CA-0.010\% CIP & $51 \pm 1$ & $77 \pm 1$ & $328 \pm 25$ & $3257 \pm 172$ & $11 \pm 0$ \\
\hline 1\% CA-0.025\% CIP & $54 \pm 2$ & $75 \pm 2$ & $295 \pm 30$ & $3877 \pm 196$ & $10 \pm 0$ \\
\hline
\end{tabular}




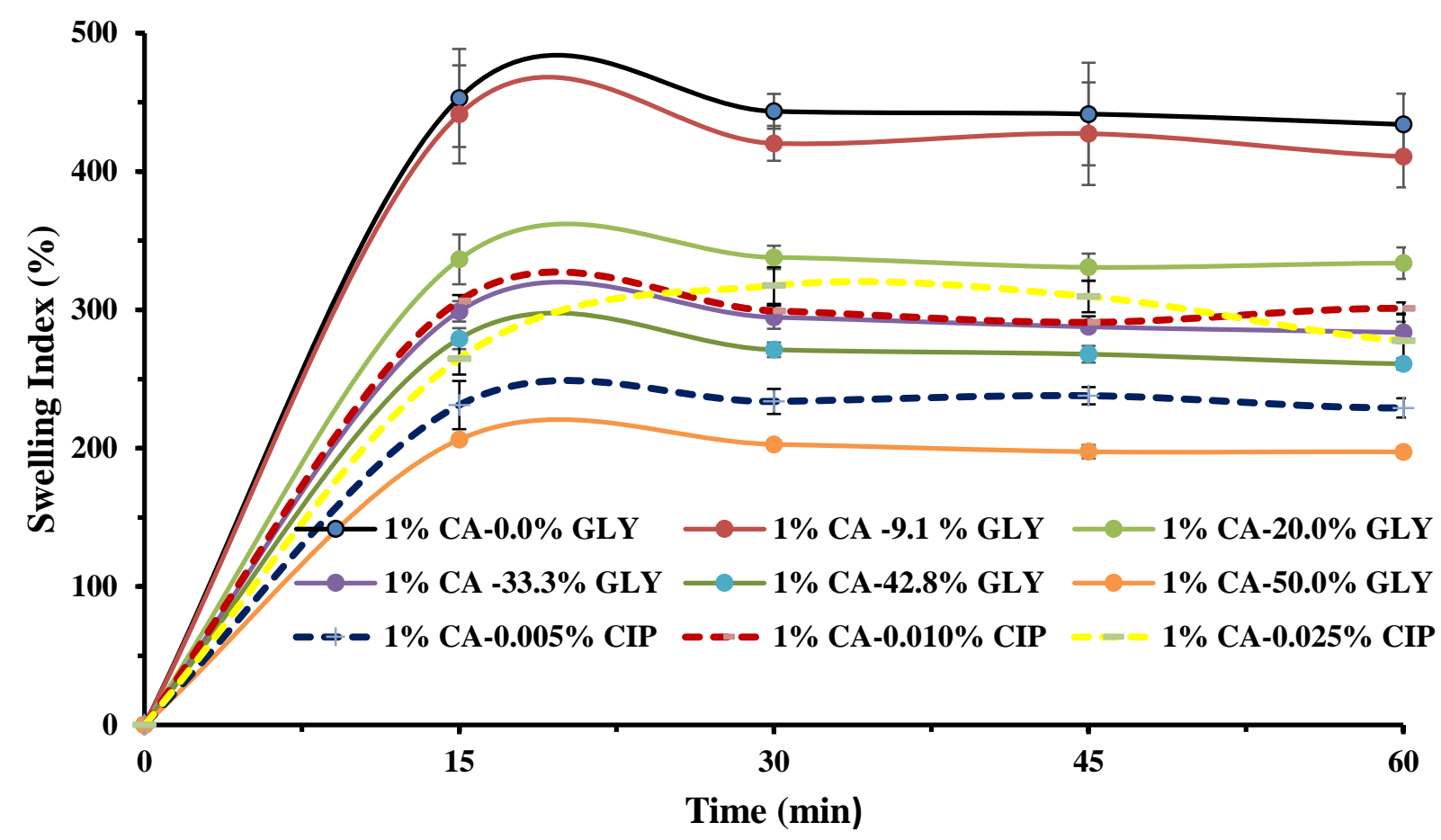

Figure 1 Swelling profiles of unplasticized, plasticized-BLK and plasticized-DL films (mean $\pm \mathrm{SD}, n=3$ ).

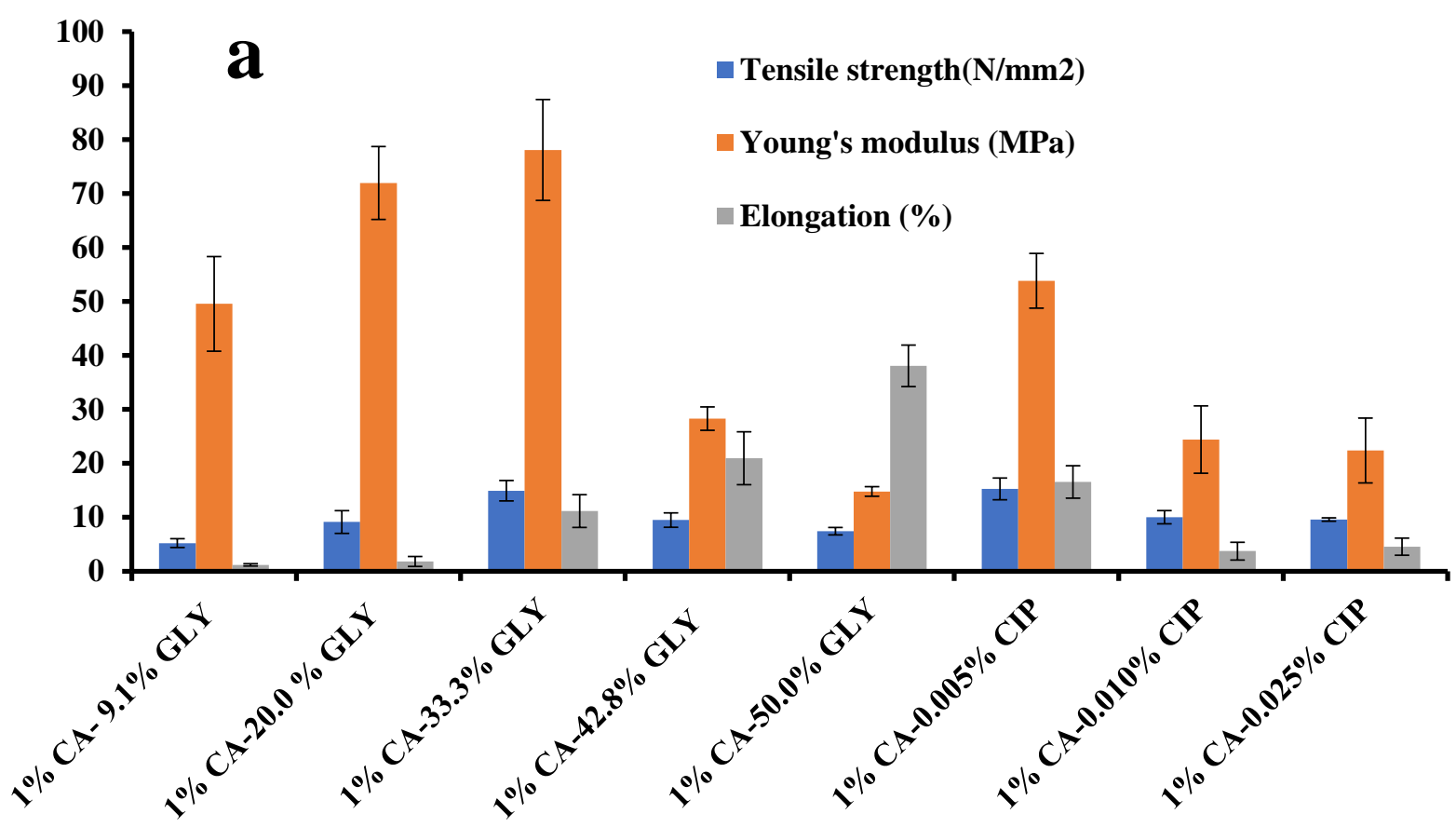




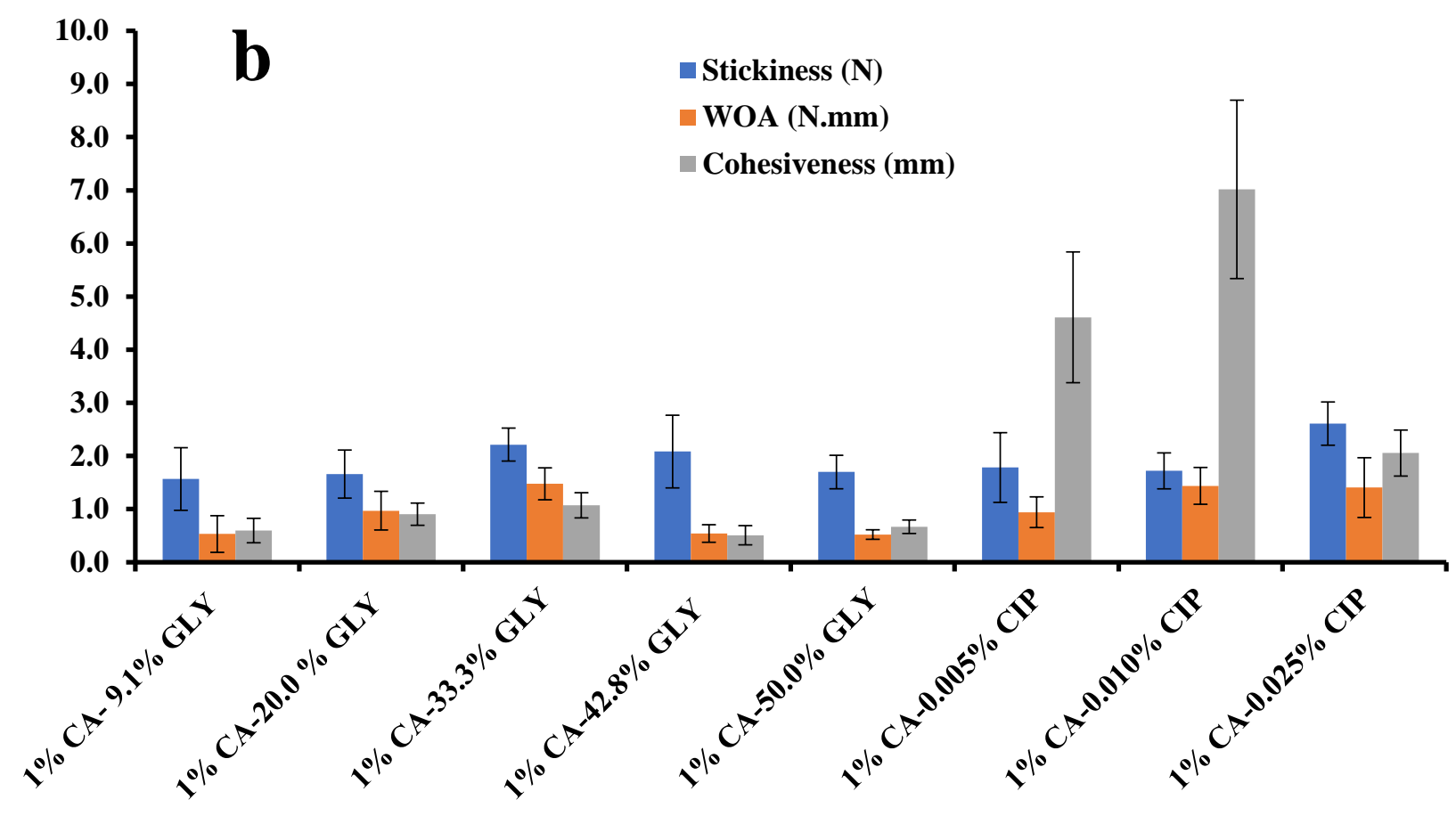

Figure 2 Texture analysis profiles showing (a) tensile and (b) adhesive results for BLK and DL films. 


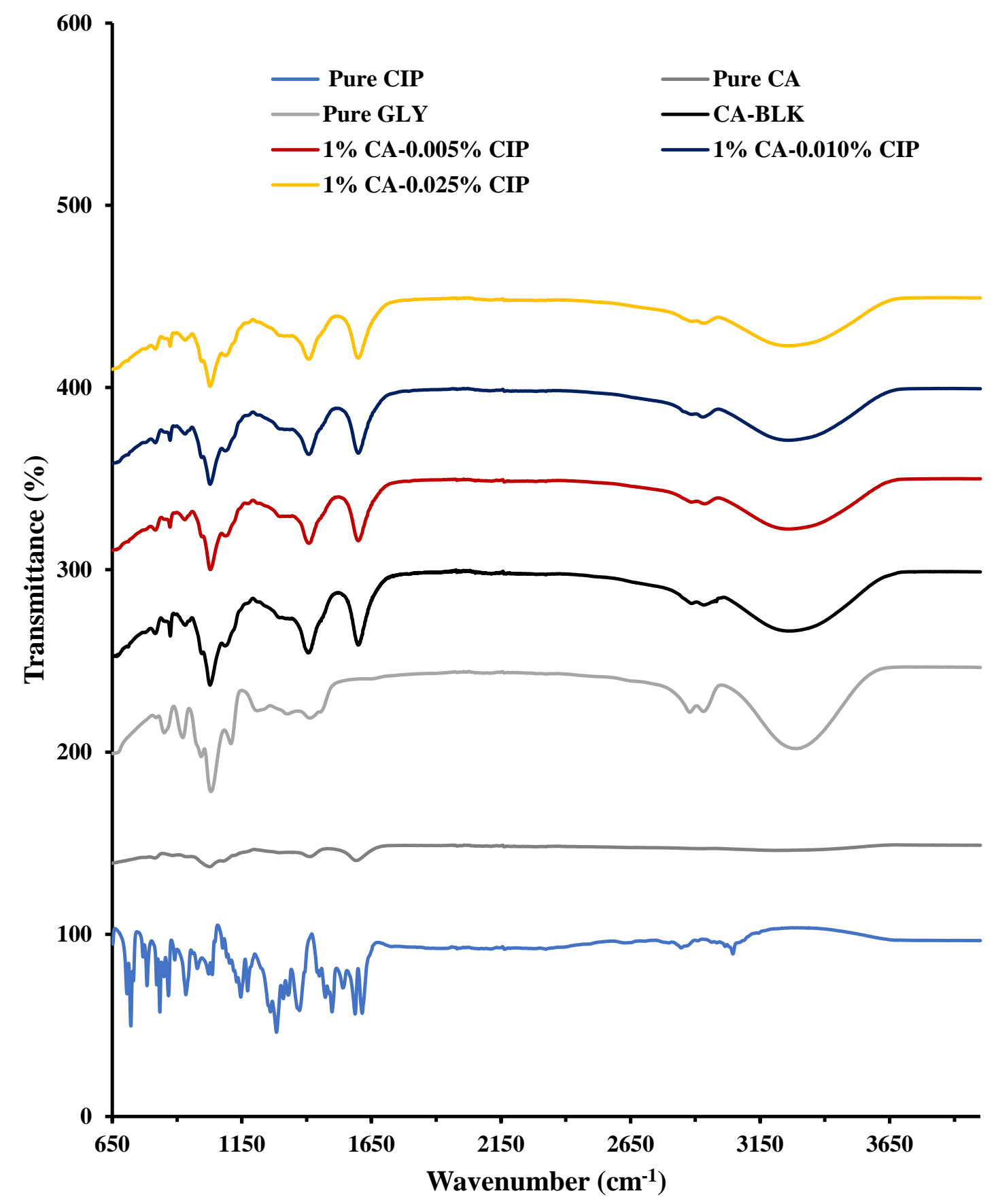

Figure 3 FTIR spectra of pure CIP, CA, GLY, CA-BLK and CA-DL films. 


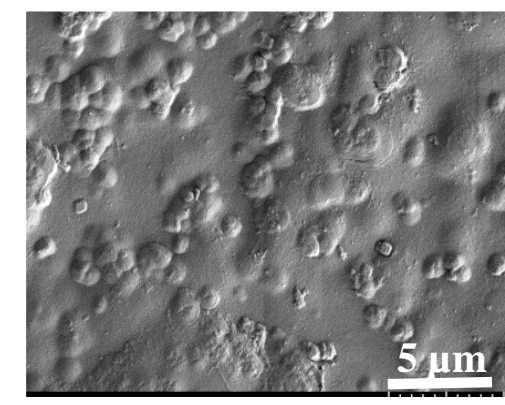

1\% CA-0.0\% GLY

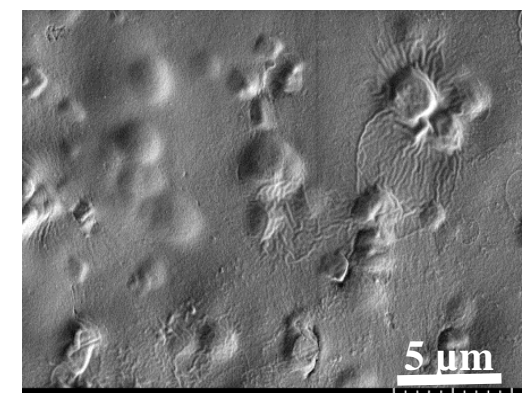

1\% CA-33.3\% GLY

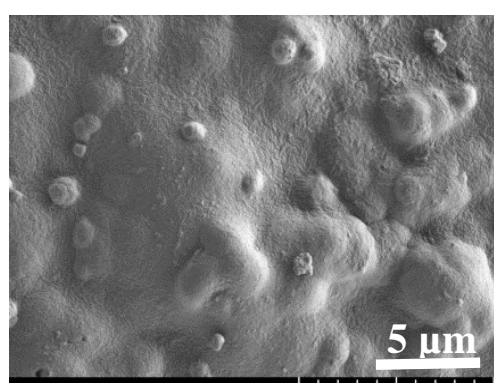

1\% CA-0.005\% CIP

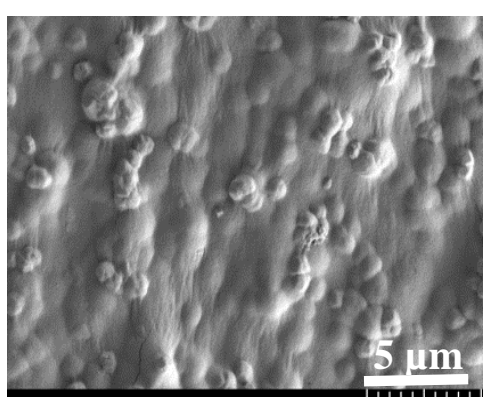

1\% CA-9.1\% GLY

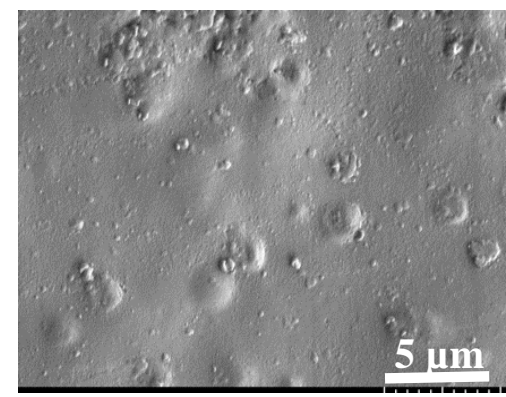

1\% CA-42.8\% GLY

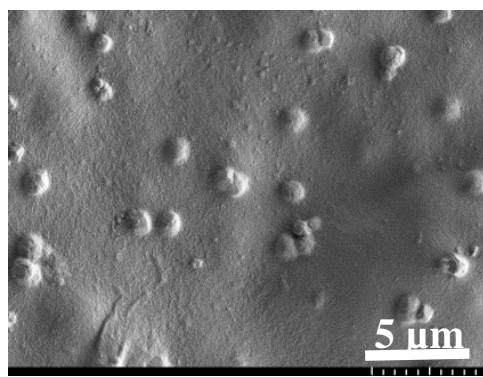

1\% CA-0.010\% CIP

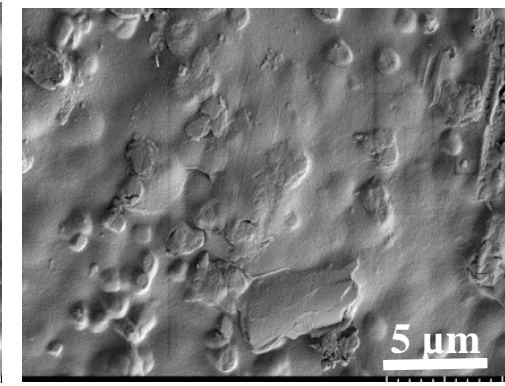

1\% CA-20.0\% GLY

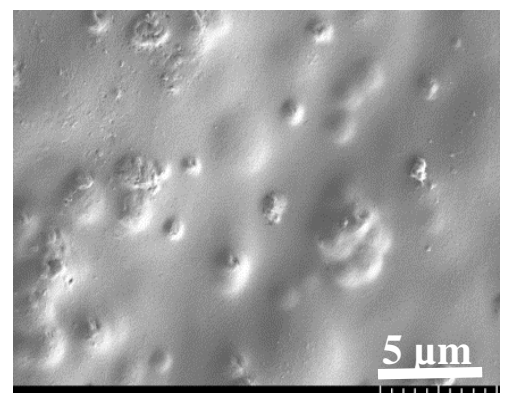

1\% CA-50.0\% GLY

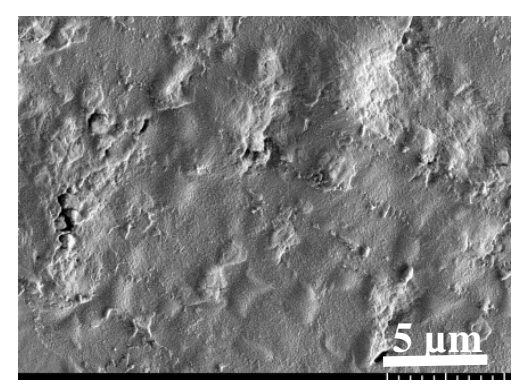

1\% CA-0.025\% CIP

Figure 4 SEM images of unplasticized-BLK, plasticized-BLK and plasticized DL films captured at x6000 magnification. 


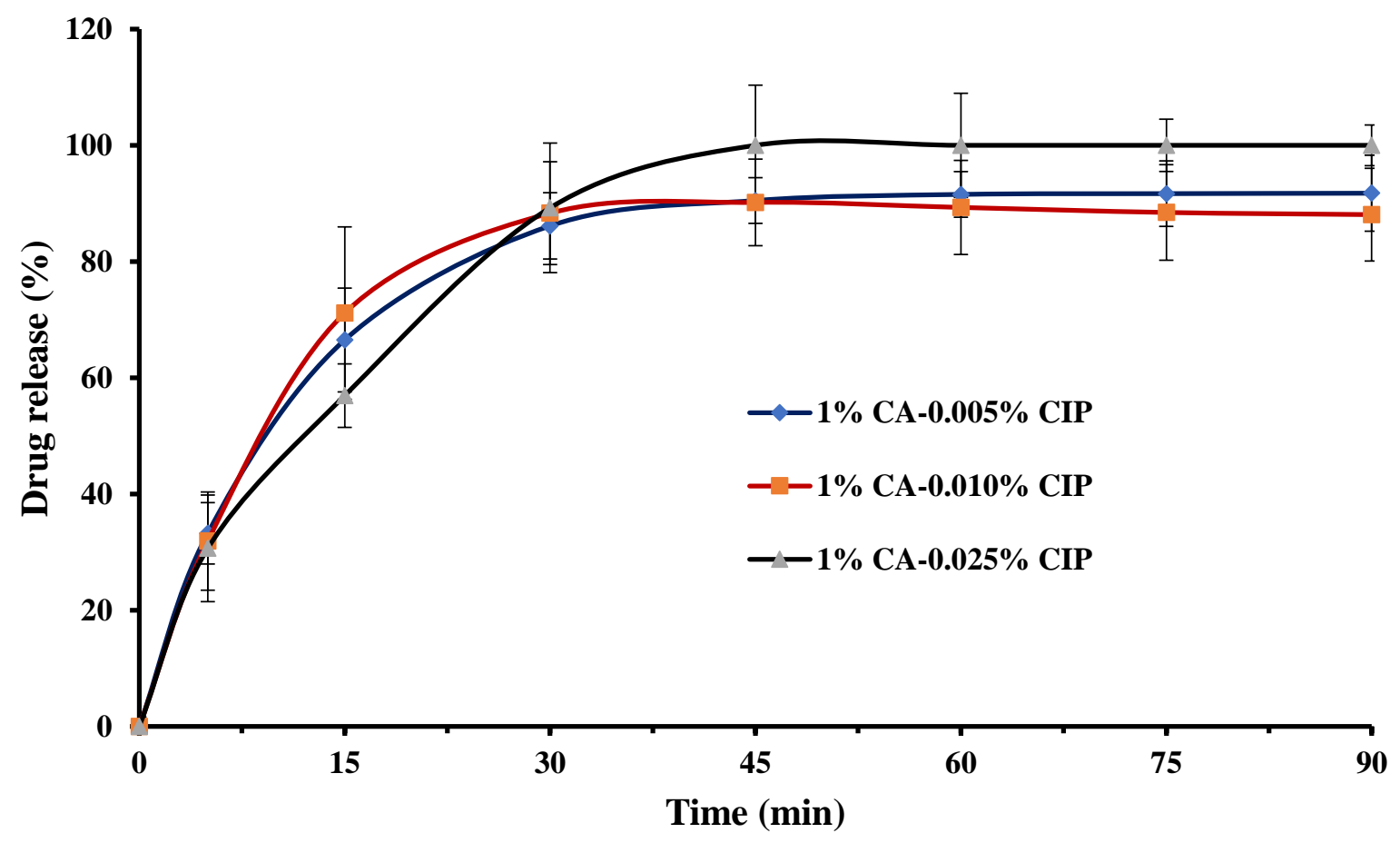

Figure 5 Cumulative percentage drug release profiles of CIP loaded films showing rapid drug release over a 90 min period. 


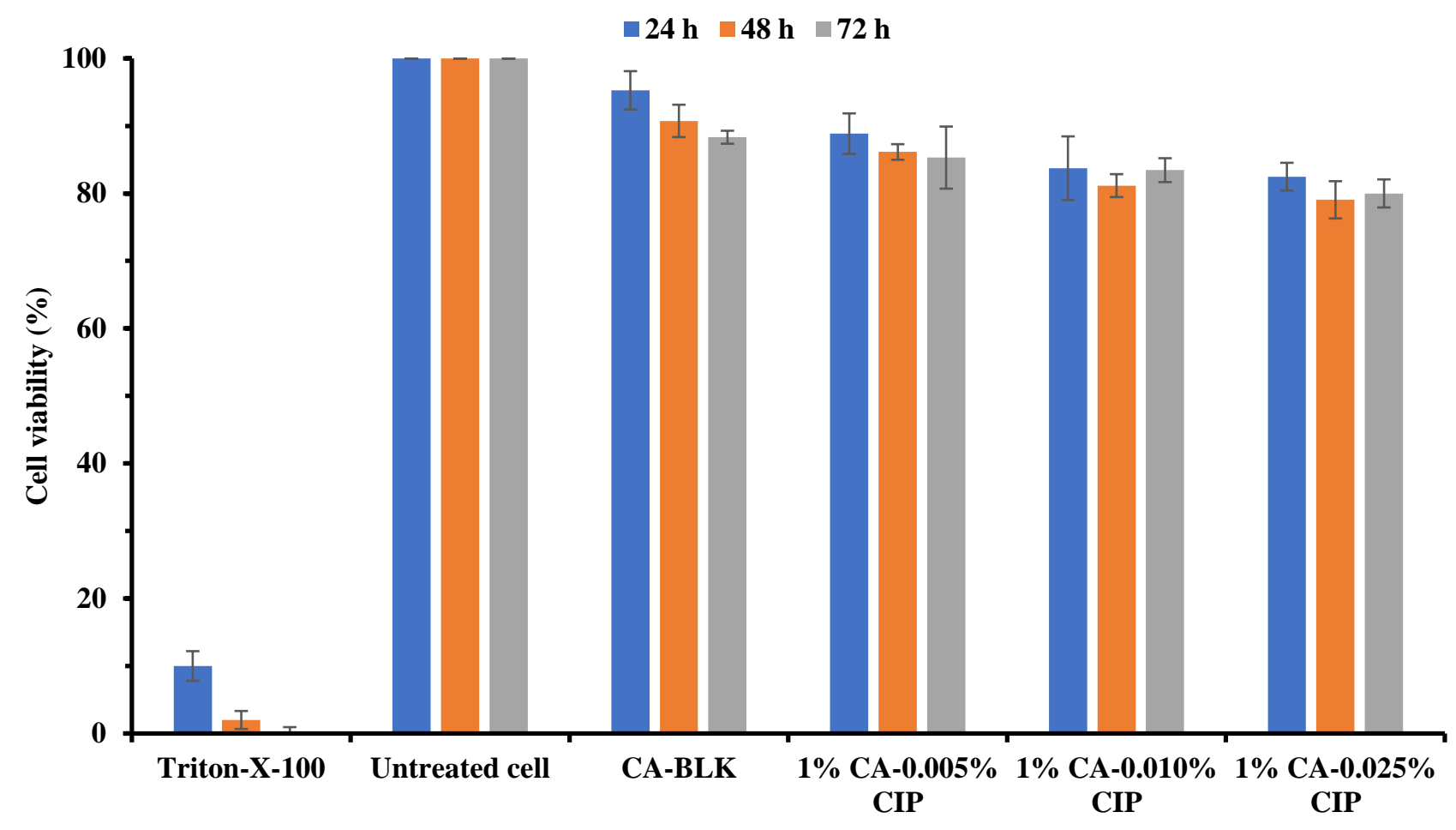

Figure 6 Cell viability of human primary epidermal keratinocytes after exposure to the extracts of BLK and CIP loaded films and Triton-X for 24, 48 and $72 \mathrm{~h}$ (mean $\pm \mathrm{SD}, n=9$ ). 

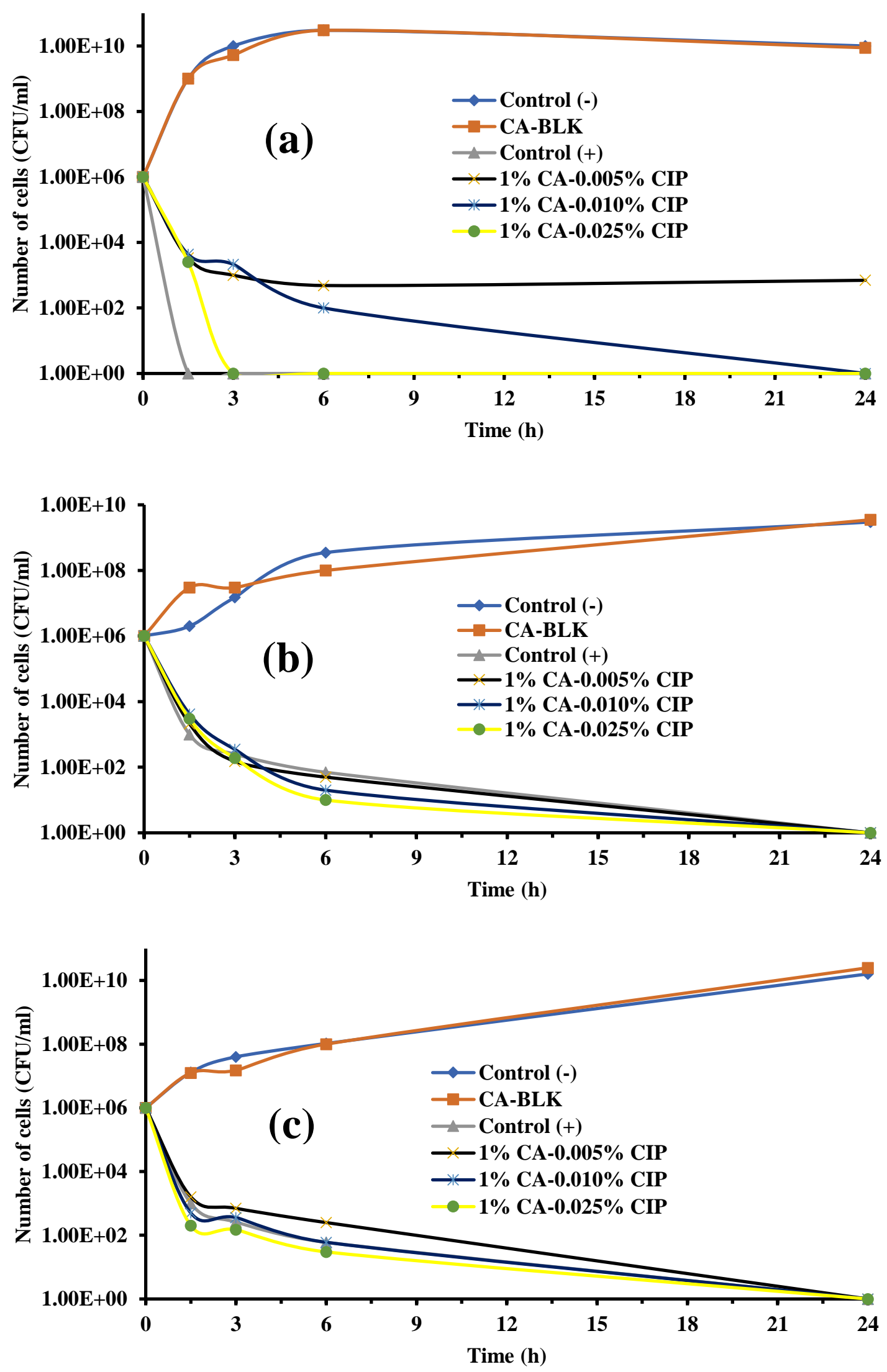

Figure 7 Rate of bacterial inhibitions after treating with CA film dressings against: (a) $E$. coli, (b) S. aureus and (c) P. aeruginosa. 